\title{
Effect of the Current-Wave Angle on the Local Scour Around Circular Piles
}

\author{
Oscar de la Torre ${ }^{1}$; Martyn Hann²; Jon Miles ${ }^{3}$; Stuart Stripling ${ }^{4}$; and Deborah Greaves ${ }^{5}$
}

\begin{abstract}
This paper studies the effect of the wave front-current angle on the scour around a circular pile. An experimental study was carried out in the Coastal, Ocean and Sediment Transport (COAST) laboratory at the University of Plymouth (UK) using a single monopile of $0.125 \mathrm{~m}$ in diameter and an $8 \mathrm{~m}$ long by $1.5 \mathrm{~m}$ wide by $0.2 \mathrm{~m}$ high sand pit. The results obtained during the test campaign show the influence of the angle between waves and currents on both the maximum scour depth and the time scale of the process. Wave fronts partially aligned with current $\left(65^{\circ}\right)$ produce deeper scour holes than perpendicular forcing conditions $\left(90^{\circ}\right)$. Wave fronts partially against the current $\left(115^{\circ}\right)$ produce less scour than any of the two previous scenarios. The addition of waves reduced the maximum scour depth, compared with the current-only case. The development of the scour hole was found to be more rapid when waves are added to the current, with $50 \%$ of the final scour achieved in half the time. The results show that wave direction relative to the current is an important component in scour prediction. DOI: 10.1061/(ASCE)WW.1943-5460.0000692. (C) 2021 American Society of Civil Engineers.
\end{abstract}

Author keywords: Scour; Monopile; Sediment transport; Wave-current interaction.

\section{Introduction}

The scour generated around a cylindrical pile has been extensively investigated in the specialized literature for many years. Breusers et al. (1977) reviewed the prevailing state of the problem, gathering a significant number of previous works involving both laboratory tests and field measurements. This rather simple geometry has been extensively studied due to it being commonplace in the building industry for bridges and offshore structures (Harris et al. 2010; Pizarro et al. 2020; Welzel et al. 2019).

Variations in the flow near cylindrical piles explain the occurrence of scour. As stated in Shen et al. (1966), the incoming flow faces an adverse pressure gradient created by the presence of the pile. This gradient can cause the detachment of the boundary layer at the bed. The detached flow together with the incoming flow deflected downwards by the cylindrical pile creates a vortex (horseshoe vortex) that contributes to the upstream scour. The wake scour is caused by a vortex-shedding phenomenon. The flow around a circular shape also faces an adverse pressure gradient after the azimuth has passed $90^{\circ}$. The boundary layer on the pile wall can then detach, creating vortices at both sides, which are carried downstream by the flow (Fig. 1).

\footnotetext{
${ }^{1}$ Senior Researcher, Barcelona Fluids \& Energy Lab, Univ. Politecnica de Catalunya, Av. Diagonal 647, 08028 Barcelona, Spain (corresponding author). ORCID: https://orcid.org/0000-0002-5814-9460. Email: dela .oscar@gmail.com

${ }^{2}$ Lecturer, School of Engineering, Univ. of Plymouth, Drake Circus, PL48AA Plymouth, UK. ORCID: https://orcid.org/0000-0003-3965-9331.

${ }^{3}$ Associate Professor, School of Engineering, Univ. of Plymouth, Drake Circus, PL48AA Plymouth, UK.

${ }^{4}$ Scientific Manager, School of Engineering, Univ. of Plymouth, Drake Circus, PL48AA Plymouth, UK.

${ }^{5}$ Professor, School of Engineering, Univ. of Plymouth, Drake Circus, PL48AA Plymouth, UK.

Note. This manuscript was submitted on February 3, 2021; approved on September 13, 2021No Epub Date. Discussion period open until 0, 0; separate discussions must be submitted for individual papers. This paper is part of the Journal of Waterway, Port, Coastal, and Ocean Engineering, (C) ASCE, ISSN 0733-950X.
}

These first investigations identified the variables involved in the phenomenon (flow conditions, object geometry, and sediment characteristics) and gave experimental and analytical results for a large variety of cases. Melville and Sutherland (1988) concluded that the largest possible scour depth for cylindrical piers is $2.4 \cdot D$. Varying factors such as sediment, flow velocity, and geometry could be seen as multiplying factors that reduce that maximum value. This upper limit has been widely accepted and included in civil works design manuals (Arneson et al. 2012) in many countries. However, for high Froude number flows maximum values of up to $3.0 \cdot D$ have been reported (Jain and Fischer 1979).

According to Zanke (1978) and Zanke et al. (2011) the critical velocity $\left(u_{C r}\right)$ to initiate the motion of the sediment can be expressed as

$$
u_{C r}=1.4\left(2 \sqrt{\rho^{\prime} g d}+10.5 \frac{v}{d}\right)
$$

where $g=$ gravitational constant; $d=$ particle diameter; $v=$ fluid viscosity; $\rho^{\prime}=\left(\rho_{s}-\rho_{f}\right) / \rho_{f}=$ relative density (with fluid's density, $\rho_{f}$, and sediment's density, $\rho_{s}$ ); and $u_{C r}=$ transition from clearwater flow conditions to live-bed flow conditions. Chabert and Engeldinger (1956) performed an extensive experimental study and showed two different behaviors depending on the regime. For flow velocities below $u_{C r}$ (clear-water conditions) the scour depth tends asymptotically to its maximum value, whereas above $u_{C r}$ (live-bed conditions) the scour depth fluctuates, due to periodic dumping of sand in the scour hole (Fig. 2).

Another expression in the literature for $u_{C r}$ can be found in Arneson et al. (2012); the critical velocity for cohesionless particles can be expressed as

$$
u_{C r}=K \cdot h^{1 / 6} \cdot d^{1 / 3}
$$

where $h=$ water depth; and $K=$ unit correction factor equal to 6.19 for S.I units.

All these works used steady flows as forcing conditions. When considering offshore structures in shallow or intermediate water depths, waves should also be taken into account. Sumer et al. (1992) carried out experimental tests to quantify the scour around circular piles caused by waves and performed a flow visualization 


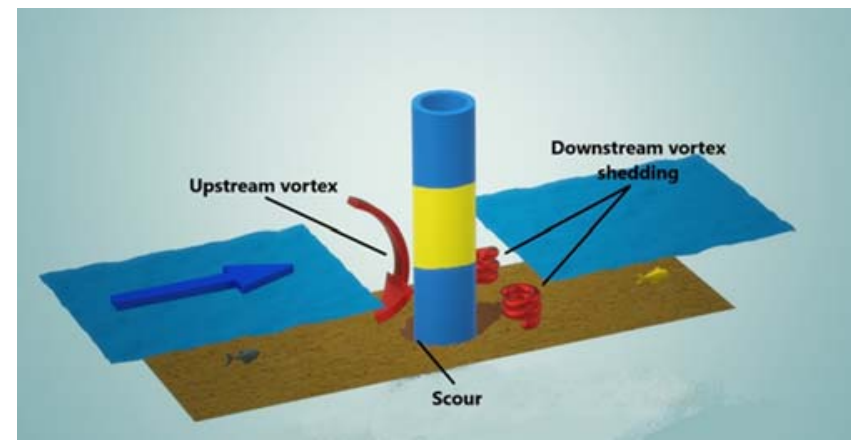

Fig. 1. Vortices causing the scour around a circular monopile.

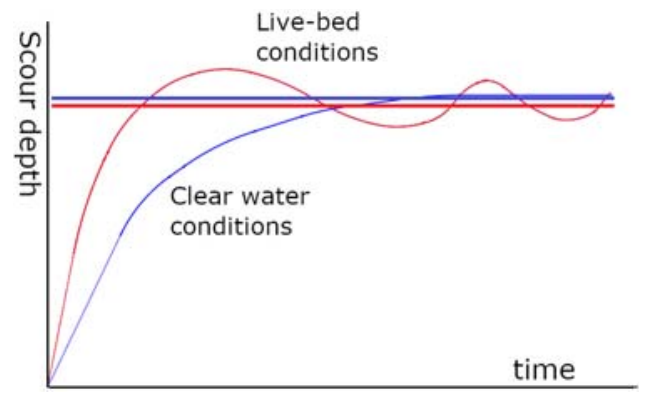

Fig. 2. Scour time evolution for different flow conditions. Maximum scour depth evolution for clear-water (top horizontal line) and live-bed conditions (bottom horizontal line). (Adapted from Arneson et al. 2012.)

study to explain how the vortices causing the scour could be generated under wave action. They concluded that the scour depends highly on the Keulegan-Carpenter $(\mathrm{KC})$ number, since there is no vortex shedding or horseshoe vortex for $\mathrm{KC}<6$. The $\mathrm{KC}$ number is defined by

$$
\mathrm{KC}=\frac{u_{m}}{f \cdot D}
$$

where $u_{m}=$ maximum orbital velocity at the sea bottom; $D=$ pile diameter; and $f=$ wave frequency.

The natural extension of these works was to combine the action of steady flow and waves. Sumer and Fredsøe (2001) analyzed these phenomena and concluded that the scour depth is a function of a combined current and wave parameter $u_{c w}$ which is defined by

$$
u_{c w}=\frac{u_{c}}{u_{c}+u_{m}}
$$

where $u_{c}=$ undisturbed flow velocity at a distance $D / 2$ from the bed. With the exception of Rudolph and Bos (2006), who performed tests with current and oblique waves, the vast majority of laboratory studies on waves and current have been restricted to aligned forcing conditions (because they are usually performed in 2-dimensional wave flumes). Recently, Schendel et al. (2018, 2020) studied the effect of directionally spread waves and oblique currents on scour around a monopile. They concluded that there is a measurable (small) effect on the scour compared with unidirectional waves and current (perpendicular). The resulting scour was larger for unidirectional waves than for multidirectional waves in waves-only conditions; for combined waves and current, multidirectional waves generated slightly larger scour depths.
According to Zanke (1982), the scour under current-only conditions follows

$$
\frac{S_{c}}{D} \cong 2.5 \cdot\left(1-0.5 \frac{u_{C r}}{u}\right)
$$

Sumer and Fredsøe (2002) presented a scour depth formula for slender piles under the combined action of waves and current as

$$
\frac{S}{D}=\frac{S_{c}}{D} \cdot\left(1-e^{-A(\mathrm{KC}-B)}\right)
$$

where

$$
\begin{gathered}
A=0.03+0.75 u_{c w}^{2.6} \\
B=6 \cdot e^{-4.7 u_{c w}}
\end{gathered}
$$

and $S_{c}=$ scour under current-only conditions. These equations are valid for the live-bed scour regime. Rudolph and Bos (2006) improved the formula due to its tendency to underpredict the scour depth in current-dominated conditions and extended its range of operation to shallower conditions using

$$
\begin{gathered}
\frac{S}{D}=1.3 \cdot\left(1-e^{-A(\mathrm{KC}-B)}\left(1-u_{c w}\right)^{0.1}\right)\left(\tanh \left(\frac{h}{D}\right)\right) \\
A=0.03+1.5 u_{c w}^{4} \\
B=6 \cdot e^{-5 u_{c w}}
\end{gathered}
$$

In Eq. (9), there is no reference to the angle between waves and current direction. In practice, waves and currents will not always be in line with each other or precisely orthogonal.

Many previous experiments have aimed to find an equilibrium scour depth. This is achieved asymptotically after a certain time as the scour reaches its maximum. There exists also a large body of literature dealing with time evolution of the scour for steady flow conditions (Raudkivi and Ettema 1983; Dey 1999) and waves and current action combined (Sumer et al. 2013; Whitehouse et al. 2006; Qi and Gao 2014). Most offer empirical regressions to quantify the time evolution.

This paper aims to compare the scour around a cylindrical monopile generated by current-only conditions, with scour generated by waves and current for different angles between the waves and current. The existing literature typically deals with aligned forcing conditions: current with either following or opposing waves and no consensus exist comparing both scour levels (Fazeres-Ferradosa et al. 2021). Particular attention is focused on examining the effect of three different wave-current angles. Further investigation is carried out to analyze the equilibrium sand bed morphology in these cases and the time dependent curves to reach it.

\section{Test Campaign}

\section{Experimental Setup}

The test program was carried out in the Coastal Basin at the University of Plymouth (UK). This basin is $15.5 \mathrm{~m}$ long by $10 \mathrm{~m}$ wide, with a maximum water depth of $0.5 \mathrm{~m}$, and has 20 full-depth absorbing piston paddles for wave generation. Bidirectional flow is available across the basin, generated by a series of pumps. The pumps are capable of dealing with sediments up to $2 \mathrm{~mm}$ grain size. Independent control of the piston paddles allows waves to be generated at a variety of angles in relation to the current.

An $8 \mathrm{~m}$ long by $1.5 \mathrm{~m}$ wide and $0.2 \mathrm{~m}$ high sand pit was built in the Coastal Basin. A $0.125 \mathrm{~m}$ diameter monopile was installed in 
the center of the sand pit. The monopile was specially designed with a removable upper section to allow a scanner carriage to pass, in between test runs, to measure high-resolution bed morphology. The pit was filled with commercial sand $\left(\rho_{s}=2.61 \mathrm{~g} / \mathrm{cm}^{3}\right)$, which was used for the whole test campaign. To obtain a better understanding of this commercial sand, three samples underwent grain size analysis. The size distribution of the sand is presented in Table 1 and Fig. 3. The experimentally determined value for $d_{50}$ was $0.29 \mathrm{~mm}$. The uniformity coefficient $\left(d_{85} / d_{15}\right)$ has been also calculated to verify the assumption of a uniform sand; a value of 1.7 validates the assumption.

A linear beach of slope 1:10 on the down-wave side of the sand pit absorbed wave energy and reduced reflections across the sand pit. Seven resistance wave probes were installed symmetrically along the pit to monitor the behavior of the wave front. A 3D acoustic Doppler profiling velocimeter (ADV) was also used during the

Table 1. Size distribution of sand for different diameters

\begin{tabular}{lcccc}
\hline$d(\mu \mathrm{m})$ & Sample 1 $(\%)$ & Sample 2 $(\%)$ & Sample 3 $(\%)$ & Average $(\%)$ \\
\hline 1,000 & 0.29 & 0.00 & 0.25 & $\mathbf{0 . 1 8}$ \\
710 & 0.00 & 0.00 & 0.00 & $\mathbf{0 . 0 0}$ \\
600 & 0.00 & 0.17 & 0.13 & $\mathbf{0 . 1 0}$ \\
355 & 9.57 & 13.33 & 8.13 & $\mathbf{1 0 . 3 4}$ \\
250 & 61.86 & 63.83 & 66.63 & $\mathbf{6 4 . 1 1}$ \\
150 & 24.57 & 19.67 & 21.88 & $\mathbf{2 2 . 0 4}$ \\
$<150$ & 3.71 & 3.00 & 3.00 & $\mathbf{3 . 2 4}$ \\
\hline
\end{tabular}

Note: Bold shows the values used for the calculation of the different sand parameters. test campaign. Figs. 4-6 show different setup views of the Coastal Basin and the sand pit.

Around the monopile, an area was defined to monitor the sand bed morphology after each tested case. A 2,350 mm long by $600 \mathrm{~mm}$ wide rectangle was scanned using a photoelectric laser distance sensor attached to a programmed traverse system, following Hartvig et al. (2010). The laser moved at a constant speed of $50 \mathrm{~mm} / \mathrm{s}$ and the sampling rate was fixed at $50 \mathrm{sam}-$ $\mathrm{ples} / \mathrm{s}$, resulting in a scan resolution of 1 point $/ \mathrm{mm}$ in the direction of movement of the traverse carriage. The laser has a $\pm 1 \mathrm{~mm}$ accuracy. Two types of scans were recorded, the longitudinal ones scanned the whole area defining parallel lines to the direction of the current flow ( $x$ axis) with a constant distance between lines of $8 \mathrm{~mm}$. The perpendicular scans scanned a $400 \mathrm{~mm}$ long by $600 \mathrm{~mm}$ wide area moving the laser in parallel lines ( $5 \mathrm{~mm}$ apart), which are perpendicular to the direction of the flow ( $y$ axis) (i.e., in the direction of wave advance for the orthogonal wave case). During the tests, four different bed locations were monitored using ultrasonic ranging sensors (Fig. 7). These sensors were used to monitor when an equilibrium bed level was reached, to assist in deciding on when to stop each test. These sensors were aligned upstream of the monopile with a center-to-center distance of approximately $2.5 \mathrm{~cm}$. Acoustic Sensor 1 was installed as close as possible to the monopile, approximately $5 \mathrm{~mm}$, carefully positioned to avoid any contact.

Different scenarios were tested with this setup:

1. current-only test,

2. waves-only test,

3. current and orthogonal waves $\left(90^{\circ}\right)$,

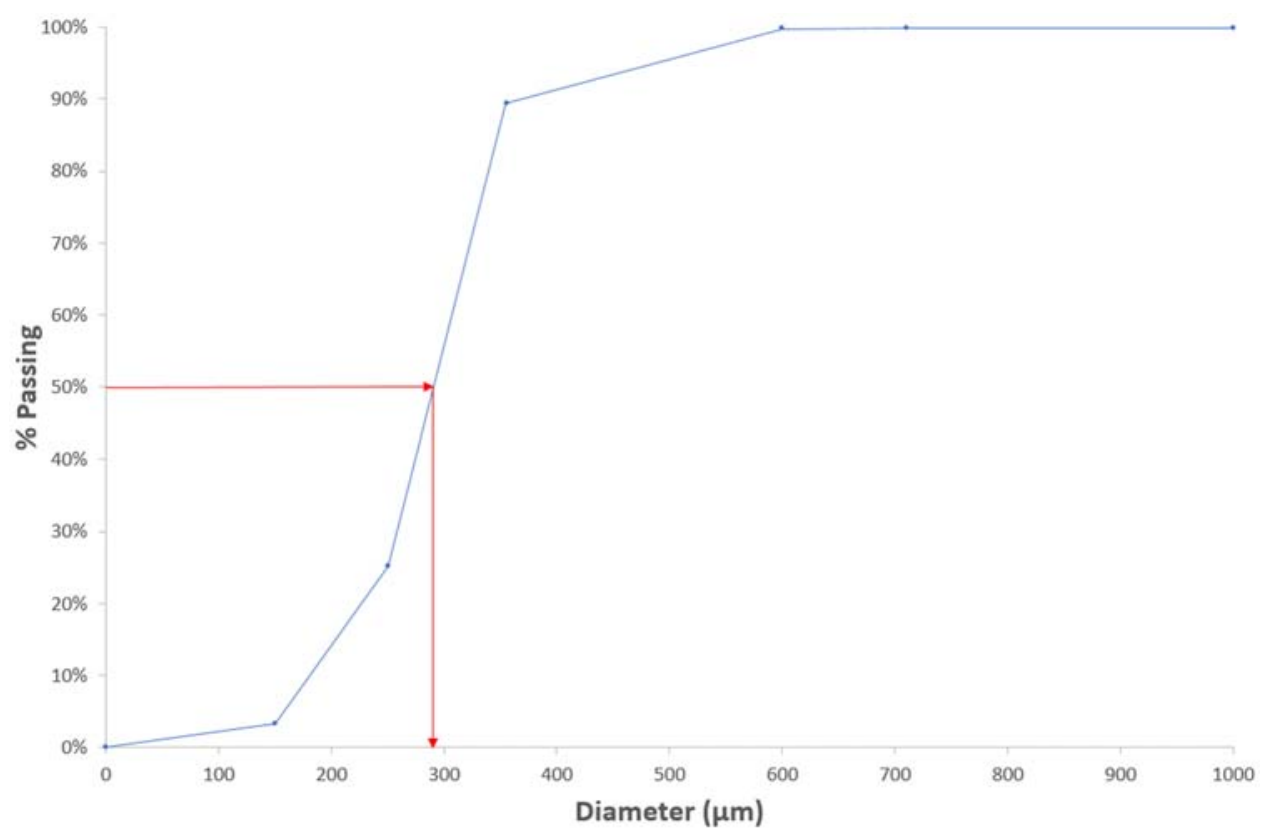

Fig. 3. Cumulative weight distribution passing corresponding sieve size and $d_{50}$ graphical determination.

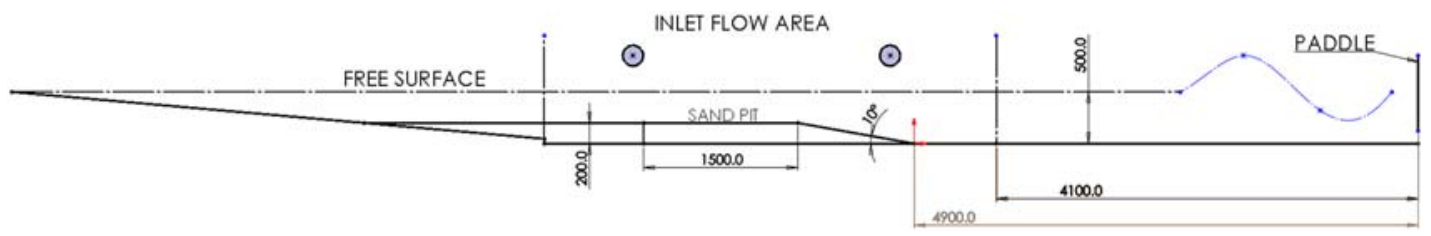

Fig. 4. Lateral view of the Coastal Basin with the installed Sand Pit (all units in millimeters). 


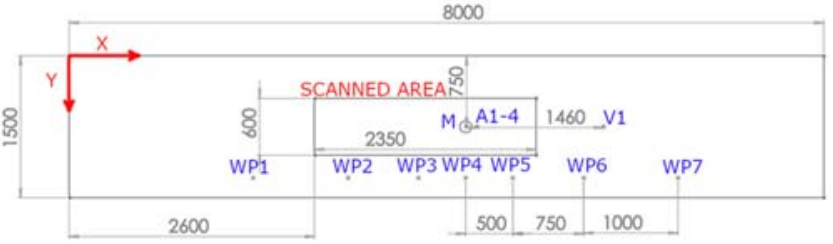

Fig. 5. Plan view of the instrumentation layout $(\mathrm{WP}=$ wave probe; $\mathrm{V}=$ Velocimeter, $\mathrm{M}=$ monopile; and $\mathrm{A}=$ ultrasonic acoustic sand level sensor). All units in millimeters.

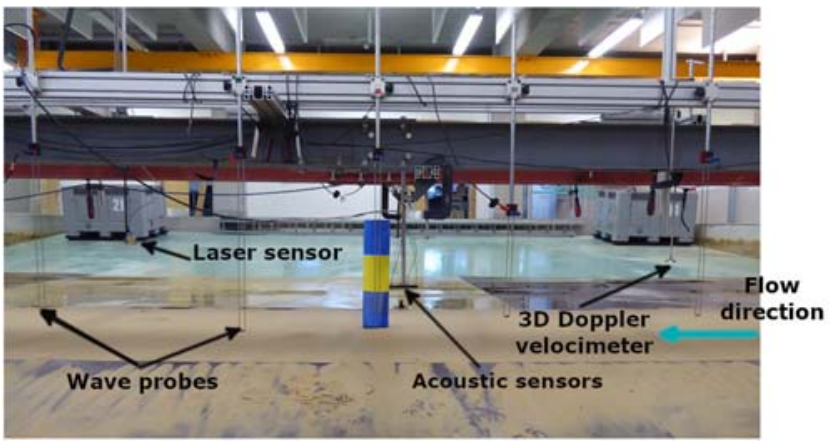

Fig. 6. Experimental setup in an empty Coastal Basin (view from the wave paddles toward the beach).

4. current and $65^{\circ}$ waves (waves with current), and

5. current and $115^{\circ}$ waves (waves against current).

The orientation of the basin, beach, and pump was such that the current flowed parallel to the beach contours in all cases, and always flowed in the same direction. The $90^{\circ}$ waves were normally incident on the beach and crossed the current at $90^{\circ}$, while the $65^{\circ}$ and $115^{\circ}$ cases approached the beach at an angle of $\pm 25^{\circ}$.

\section{Flow Test Conditions}

To choose the hydrodynamic conditions to perform the tests, it was decided that the current velocity and maximum orbital velocities should be similar in magnitude so that there was no clear dominance of one phenomenon over the other. Values of current speed and wave orbital velocity were therefore selected such that the value of $u_{c w}$ was in the range

$$
0.45<u_{c w}<0.55
$$

The preceding critical velocity equations give different results for $u_{C r}$ for the tested conditions $\left(d=d_{50}=0.29 \mathrm{~mm} ; h=0.3 \mathrm{~m}\right)$, in particular $u_{C r}=0.24 \mathrm{~m} / \mathrm{s}$ using Eq. (1) and $u_{C r}=0.335 \mathrm{~m} / \mathrm{s}$ using Eq. (2).

A mean flow velocity of $u=0.27 \mathrm{~m} / \mathrm{s}$ was selected for all the tested cases. This velocity would produce a live-bed regime according to Eq. (1) but clear-water regime according to Eq. (2). The selected velocity was a compromise between accelerating the process to reach scour equilibrium, while keeping the maximum scour depth within the sand pit depth $(<0.2 \mathrm{~m})$. The velocity value and the relative location of the scanned area also guaranteed that the flow was fully turbulent within the region of interest. The Reynolds number at the beginning of the scanning area ( $L_{x} \cong 2.9 \mathrm{~m}, \mu=1$. $10^{-3} \mathrm{~Pa} \cdot \mathrm{s}$ and $\rho_{f}=1,000 \mathrm{~kg} / \mathrm{m}^{3}$ ) was

$$
\operatorname{Re}=\frac{\rho_{f} u L_{x}}{\mu} \cong 7.8 \times 10^{5}
$$

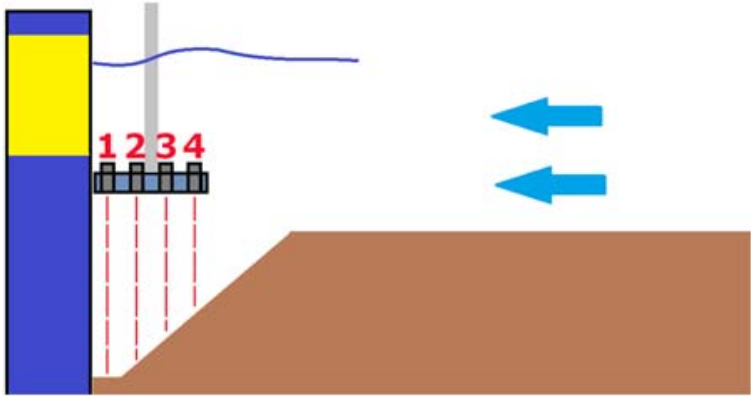

Fig. 7. Upstream scour hole and relative location of numbered acoustic sensors.

\section{Wave Conditions}

The basin was calibrated so that the same wave height was generated for the three wave angles tested. This was done using WP4, which was located closest to the monopile location and so best represented the wave loading. Wave height calibration was conducted with the sand pit filled but the monopile not installed and there was not any current. The wave heights at WP4 for all tests were $0.114 \pm$ $0.003 \mathrm{~m}$. The maximum wave height difference found within the scanned area (WP2 to 5) was $9.9 \%$. The selected frequency for the waves was $f=0.85 \mathrm{~Hz}$.

Linear theory was used to calculate the wavelength, using the wave period and water depth. Solutions were compared with those using the approach of Fenton (1985) for higher-order waves. The linear theory results were found to be within $3 \%$ of the higher-order cases. Linear theory was therefore applied in calculating wavelengths and KC numbers (Dean and Dalrymple 1991).

Although Sumer et al. (1992) found the threshold KC value for wave-only scour to be 6 , some researchers still quantify the scour generated by waves for $4<\mathrm{KC}<6$ (Sumer and Fredsøe 2001; Rudolph and Bos 2006). In the present work, the selected wave conditions indicated that no wave-only scour should be generated because $\mathrm{KC}=2.16<4<6$.

\section{Test Procedure}

In order to ensure consistency between test runs, the same procedure for sand bed preparation and subsequent morphology measurement was followed for each test in the campaign.

The sand pit was filled with sand and leveled, then the upper part of the monopile was (re-)installed and the ultrasonic sensors fixed in position. Subsequently, the Coastal Basin was filled with water up to a depth $h=0.5 m \pm 1 \%(h=0.3 m \pm 1 \%$ above the sand pit). The test was run until scour equilibrium was reached, and once the run was completed, the Coastal Basin was drained. After that, the upper part of the monopile and the ultrasonic sensors were temporarily removed, and the sand pit was scanned. The procedure was then restarted.

\section{Results}

\section{Current-Only Case}

A current-only test was carried out as a reference, at the $u=0.27$ $\mathrm{m} / \mathrm{s}$ flow velocity. The test was left running for $26.8 \mathrm{~h}$. Once the whole test program was finished, the current-only case was repeated to verify that the pumps' performance did not degrade 


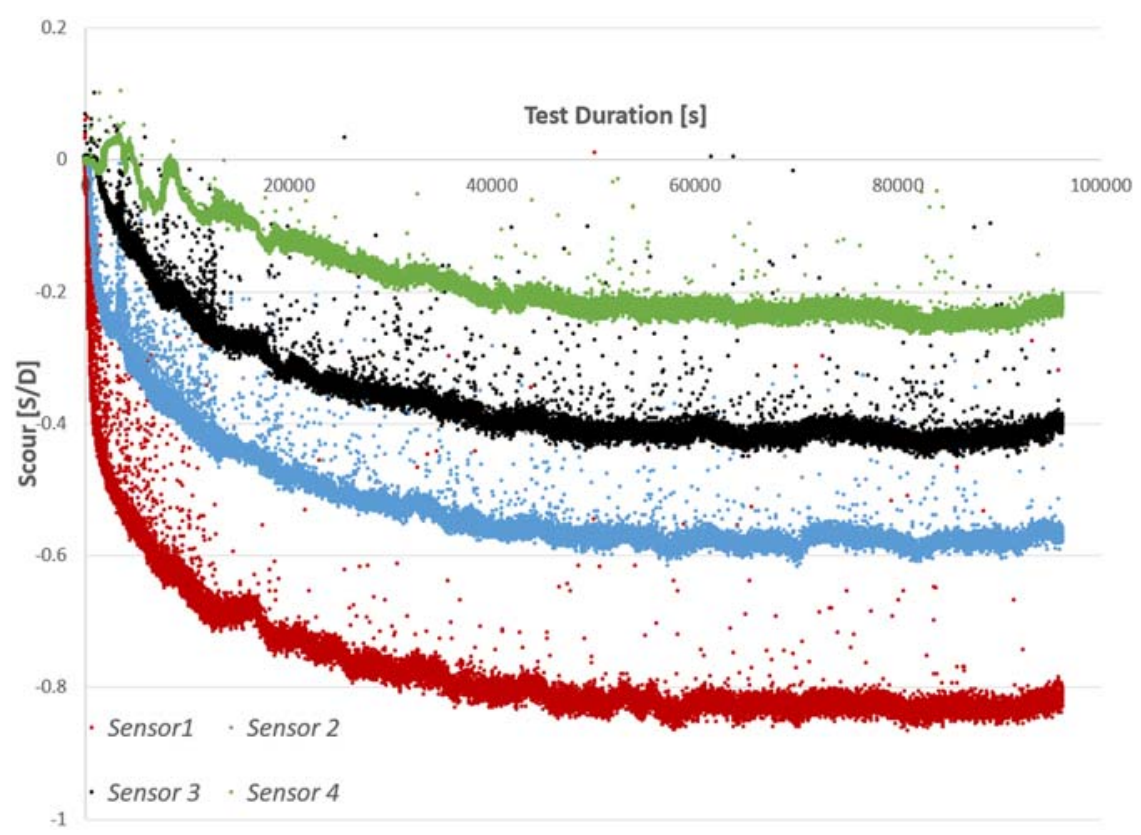

Fig. 8. Scour depth time evolution for the acoustic sensors for current-only case. The scour depth values indicate the distance of the bed below the original bed level.

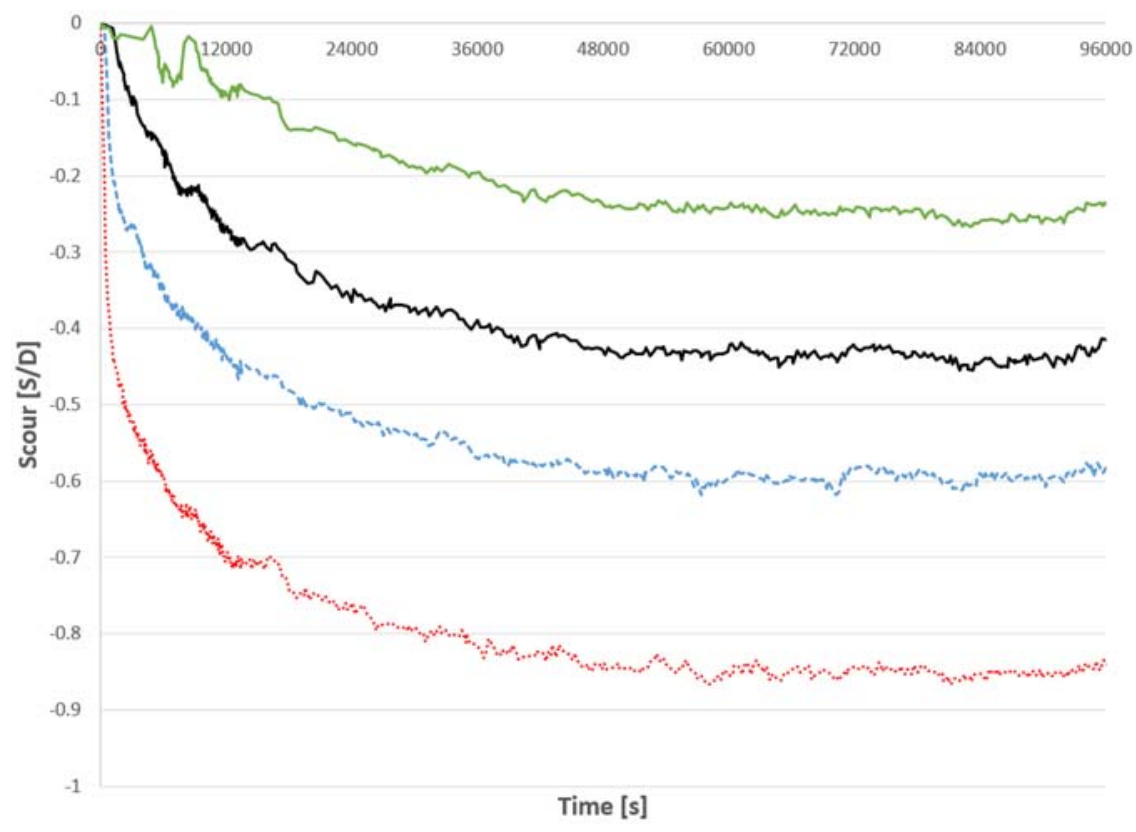

Fig. 9. Postprocessing tool: envelope plot (bottom dotted line: Sensor 1, square dotted line: Sensor 2, darker solid line: Sensor 3, and top solid line: Sensor 4).

during the campaign. Fig. 8 shows the results obtained with the set of four acoustic sensors. Sensor 1 is the closest to the monopile.

As observed, the sensors showed a clear equilibrium when the test was stopped. Comparing these results with Fig. 2, the time signals seem to indicate that the flow conditions were consistent with the "clear-water" regime definition. However, the evident presence of ripples in the sand bed at the end of the test indicates otherwise. Therefore, Eq. (1) was accepted as valid and the critical velocity for the experiment setup taken as $u_{C r}=0.24 \mathrm{~m} / \mathrm{s}$.

A certain level of noise within the signals is noticeable above the clearly defined lower signal envelope. It has been assumed that this lower envelope represents the actual bed height and that the noise is likely due to the presence of suspended particles in the flow.

Outlier values were filtered out by removing a given point if it fell outside a selectable margin (typically 50\%) of the previous valid reading. The lower envelope of the filtered signal was then obtained by plotting the minimum value of a sliding time-window of selectable time width (between 30 and $50 \mathrm{~s}$ depending on the case) (Fig. 9). The average scour of all data points of each envelope during the last hour of test was taken as the equilibrium scour values.

The bed morphology at the end of the test is shown in Fig. 10 as a level plot. The current flows from right to left. There is a 


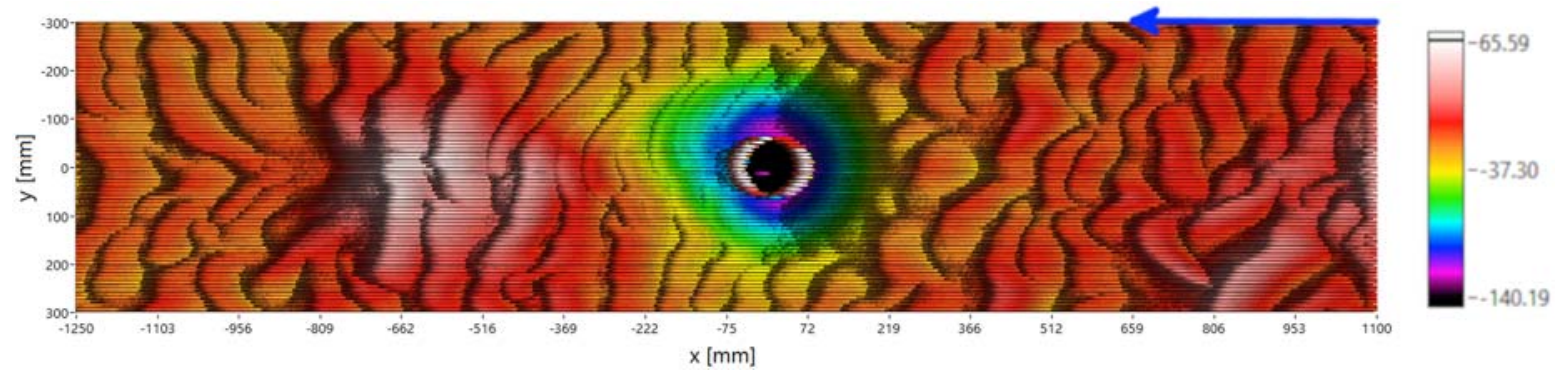

Fig. 10. Level plot showing the final bed morphology for current-only case. The vertical scale units are millimeters. Top right arrow indicates the current direction.

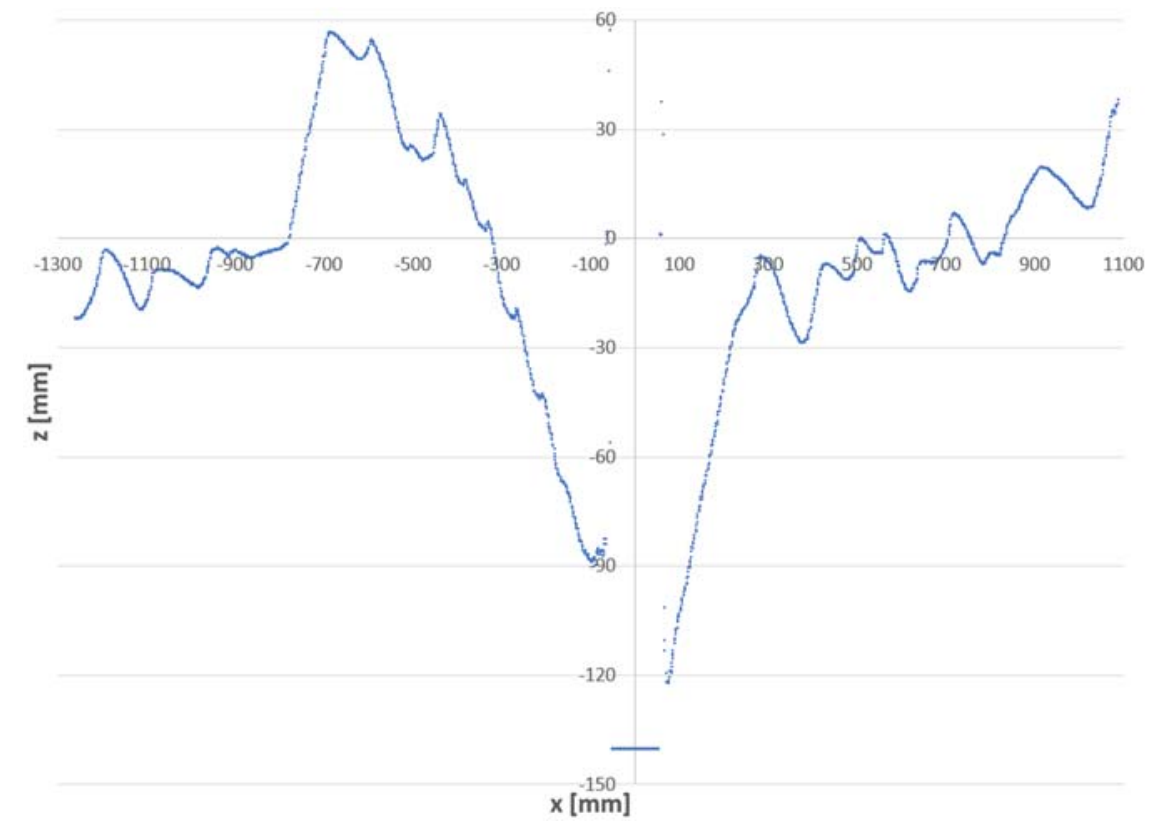

Fig. 11. Profile shape (at $y=0$ ) for current-only case at the end of the test, $z=0$ indicates the bed level at the start of the test.

deposition area approximately $5 \mathrm{D}$ downstream of the monopile location, with a height above initial mean bed level of up to $57 \mathrm{~mm}$. The scour affected an area around the monopile of approximately 3.5 D. The scour hole is deepest on the upstream side, as shown in Fig. 11, which shows the $y=0$ bed level profile.

The profile shows a scour hole slope in the region $x \in[100,200]$ of $32.5^{\circ}$, which lies within the typical range given by Hoffmans and Verheij (1997). The map plot shows current ripples forming in the regions away from the pile perpendicular to the direction of the flow. Upstream of the pile the average wavelength of these ripples is $212.7 \pm 34.6 \mathrm{~mm}$ and their averaged height, $18.1 \pm 1.0 \mathrm{~mm}$. Although computational errors arose due to resolution, aliasing the angle of the ripple crest, and variability over the ripple field are possible, these values broadly matched the direct visual observations taken during the experiments.

Fig. 12 shows the state of the sand bed after the test.

\section{Waves-Only Case}

A wave-only case was run to test the assumption that no scour would be generated under waves only, because $\mathrm{KC}<6$. As such, this test was left running long enough to observe the general trend with the acoustic sensors ( $2 \mathrm{~h}$ approximately). This case showed rather noisier results than any other tested case. One

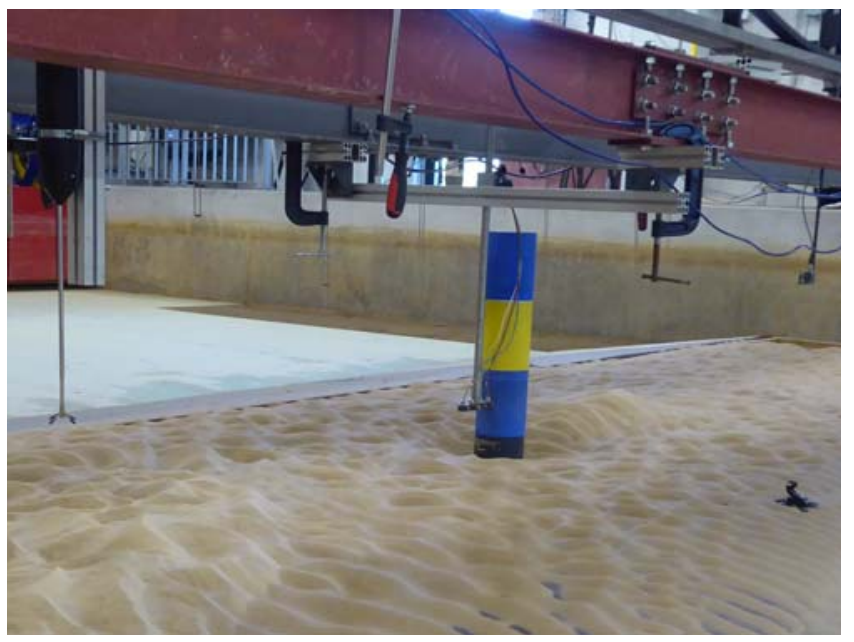

Fig. 12. Final state of the sand bed for current-only case (flow from left to right).

possible reason for this is that the absence of current left the sand particles oscillating widely below the sensors. Fig. 13 shows the lower envelopes of each sensor. As observed, there is no clear 


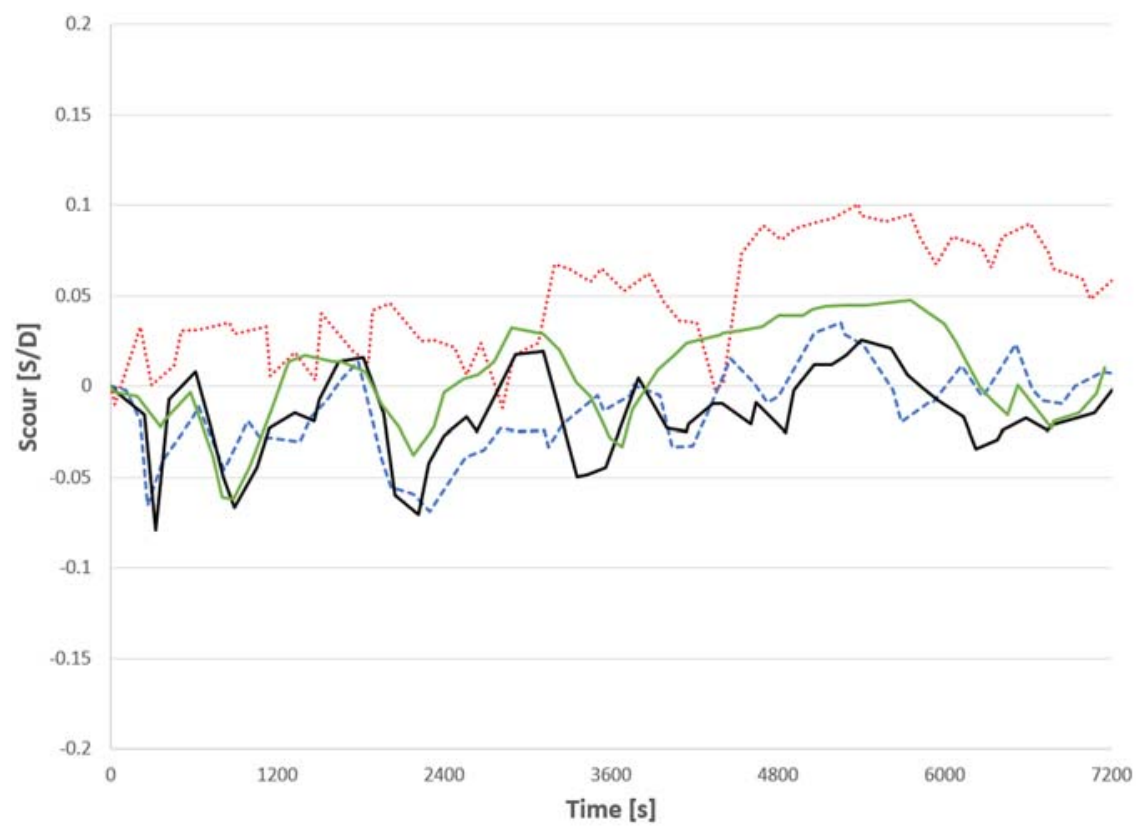

Fig. 13. Lower envelopes for the acoustic sensors for waves-only case (round dotted line: Sensor 1, square dotted line: Sensor 2, darker solid line: Sensor 3, clearer solid line: Sensor 4).

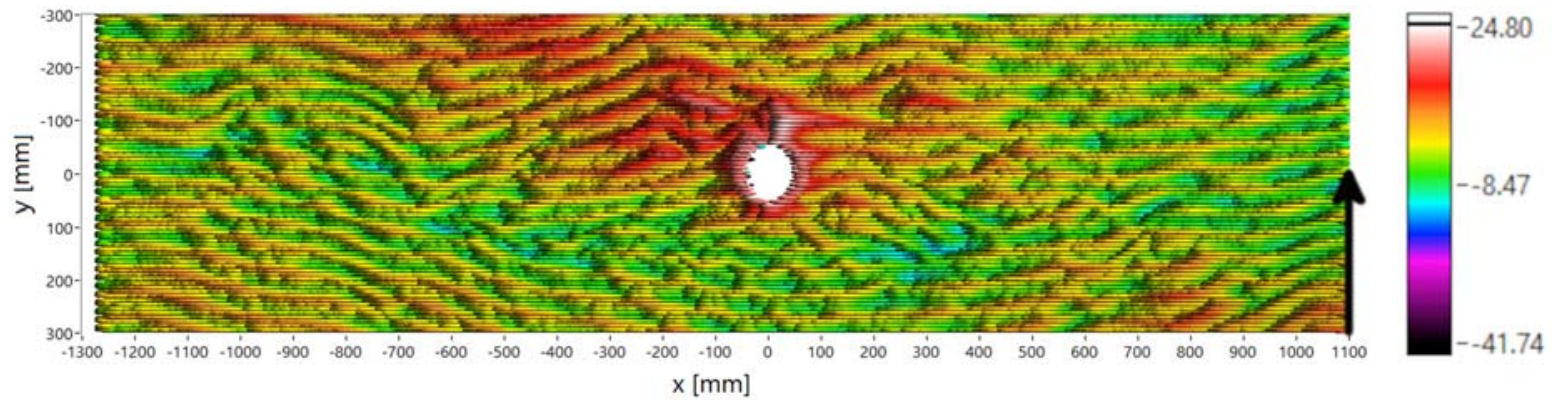

Fig. 14. Level plot showing the final bed morphology for waves-only case. The vertical scale units are millimeters. Bottom right arrow indicates the wave propagation direction.

scour trend for Sensors $2-4$, which suggests that variation in bed level is most likely to be related to observed ripple movement. Sensor 1 seems to be showing some deposition around the monopile for the second half of the test.

The sand pit was also scanned at the end of the test. Fig. 14 shows the final bed morphology. As observed, the sand ripples are parallel to the wave front over the whole scanned area (waves traveling from bottom to top). It is clear that no signs of scour are visible around the monopile by the time the test was stopped. The $y=0$ profile shown in Fig. 15 looks flat for its whole length. This plot appears to show a disruption to the ripple morphology and a small amount of accretion near the pile. Clearly, the pile is having an effect on sediment transport, but the net movement is not away from the pile, so this wave-only case does not generate scour at any point around the pile. Analysis of the surface suggests an average ripple wavelength of $42.5 \mathrm{~mm}$ and height of $7.9 \mathrm{~mm}$.

\section{Current and $90^{\circ}$ Waves}

A test case was run with a current of $0.27 \mathrm{~m} / \mathrm{s}$ and waves at $90^{\circ}$ to the current. This case was tested for approximately $6 \mathrm{~h}$ until reaching the equilibrium. Fig. 16 shows the lower envelopes of each of the acoustic sensors.

The bed morphology is shown in Fig. 17. The current goes from right to left and the wave front moves from bottom to top. The sand ripples are not perpendicular to the flow upstream of the monopile in this case but form a fairly regular angle with the flow (39 approximately). Angled ripples make their numerical analysis less accurate since the scan resolution in the $y$-axis is 1 point every $8 \mathrm{~mm}$. Therefore, qualitative analysis only is given for these cases. The $y=$ 0 profile is shown in Fig. 18. The scour hole slope in the region $x \in$ $[100,200]$ is $30.9^{\circ}$.

\section{Current and $65^{\circ}$ Waves}

A test was run with currents at $0.27 \mathrm{~m} / \mathrm{s}$ and waves at an angle of $65^{\circ}$ to the currents. Waves were therefore broadly traveling "with" the current, albeit at an angle to it. The test was left running for approximately $6 \mathrm{~h}$ until reaching equilibrium. Fig. 19 shows the lower envelopes of each of the acoustic sensors for this case.

The sand bed final morphology is shown in the level plot of Fig. 20. The current moves from right to left and the wave front also runs from right to left, bottom to top. As observed, angled 


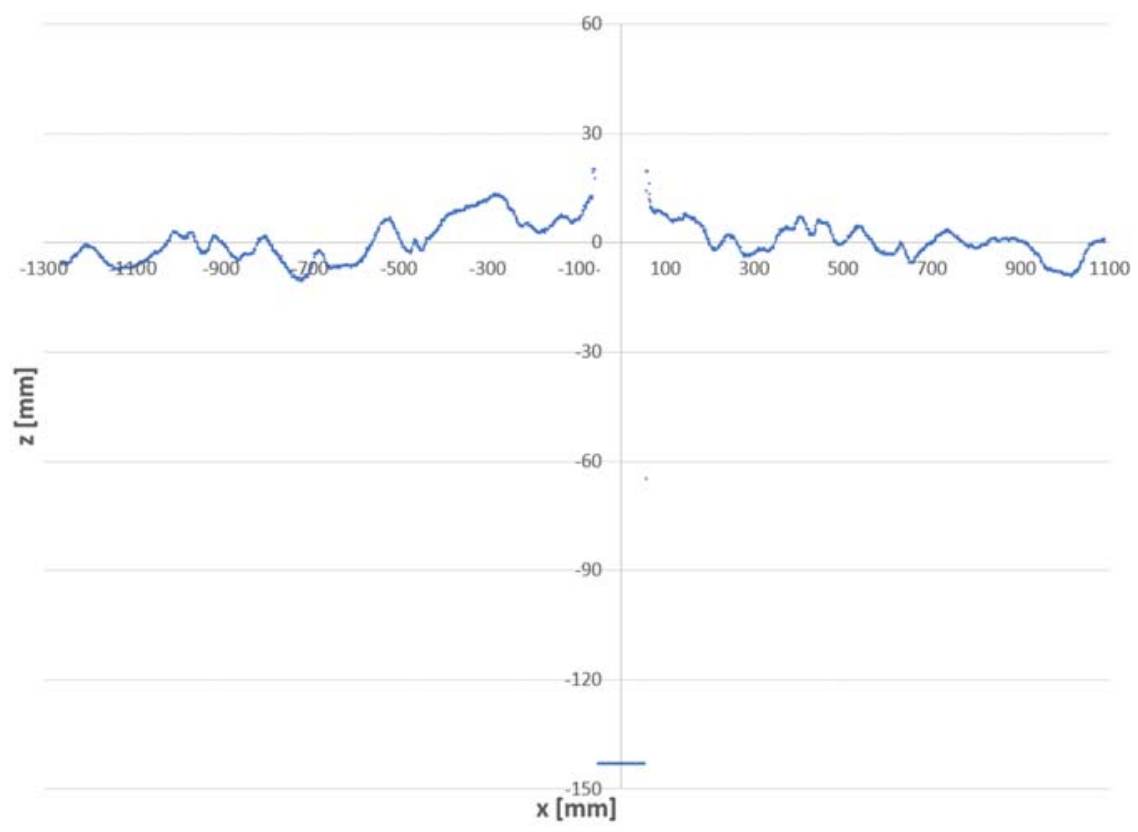

Fig. 15. Profile shape (at $y=0$ ) for waves-only case at the end of the test, $z=0$ indicates the bed level at the start of the test.

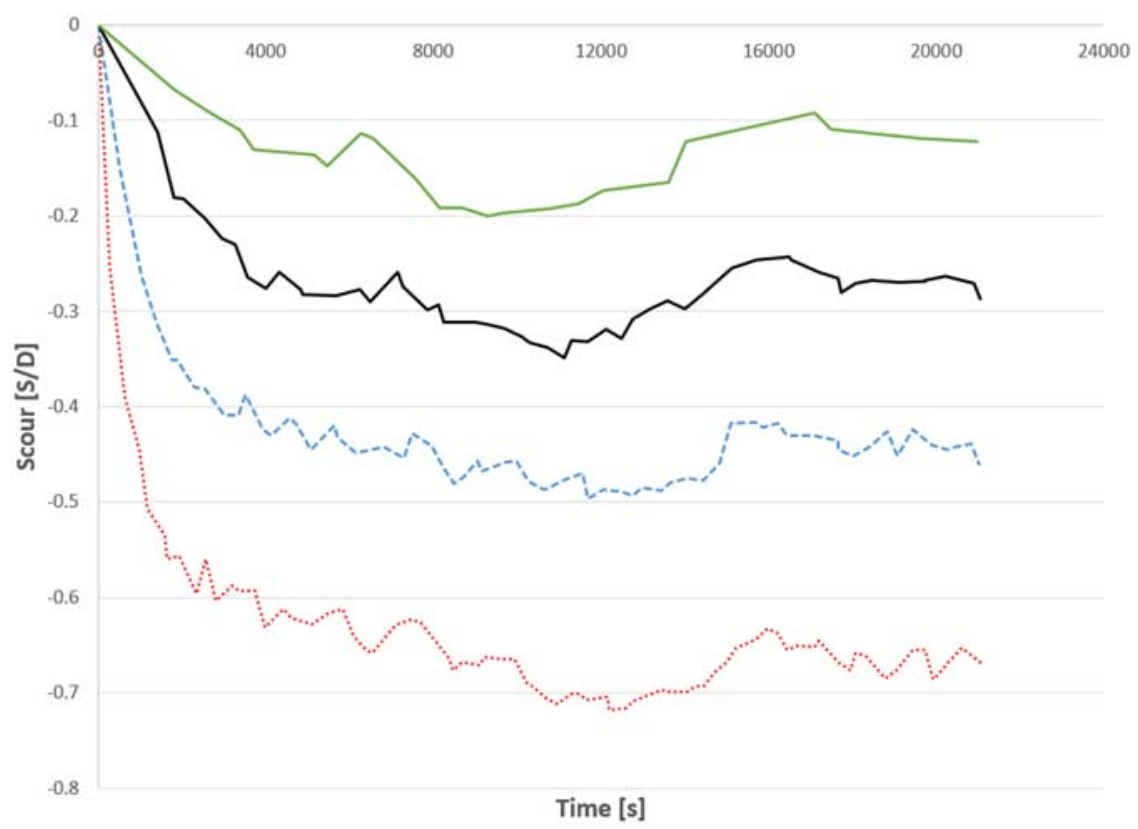

Fig. 16. Lower envelopes for the acoustic sensors for current and $90^{\circ}$ case (round dotted line: Sensor 1, square dotted line: Sensor 2, darker solid line: Sensor 3, top solid line: Sensor 4).

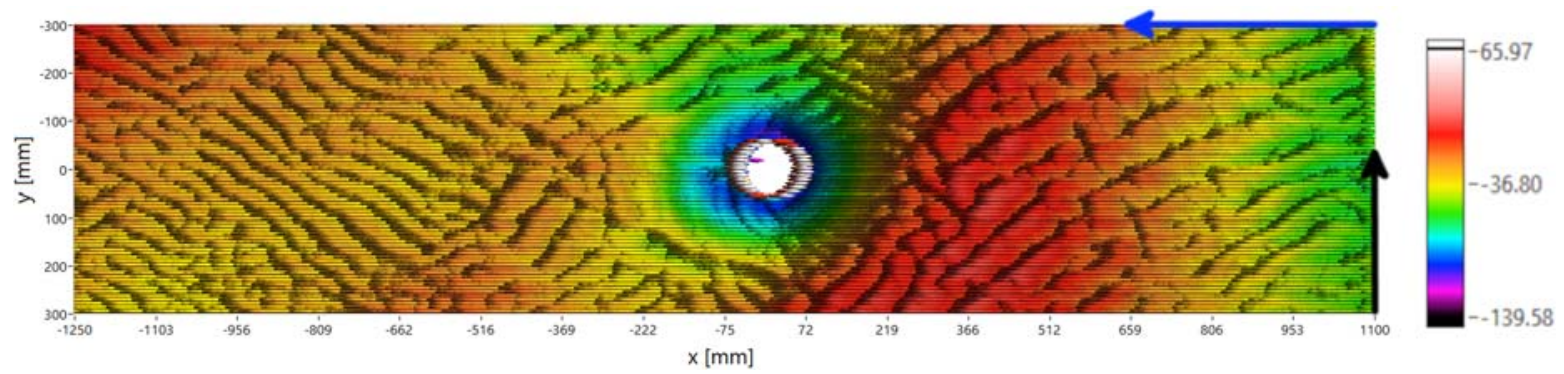

Fig. 17. Level plot showing the final bed morphology for current and $90^{\circ}$ case. The vertical scale units are millimeters. Top right arrow indicates current direction and bottom right arrow indicates the wave propagation direction. 


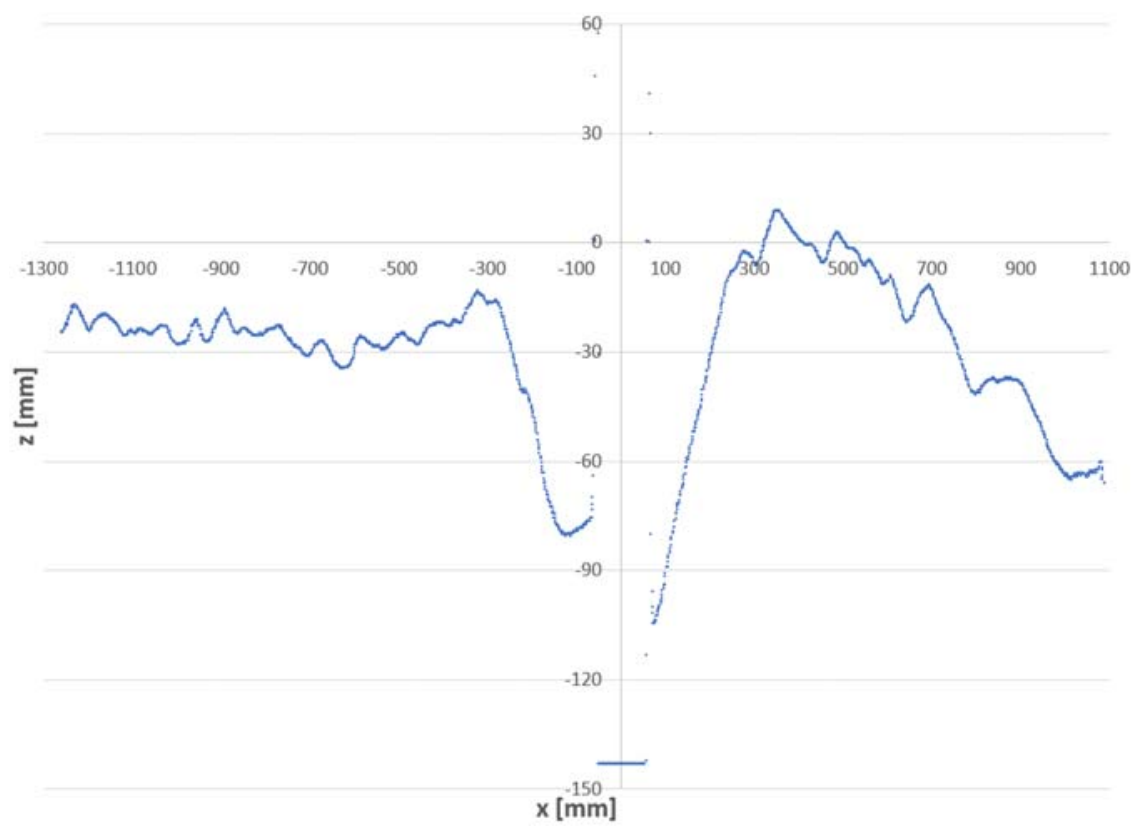

Fig. 18. Profile shape (at $y=0$ ) for current and $90^{\circ}$ waves case at the end of the test, $z=0$ indicates the bed level at the start of the test.

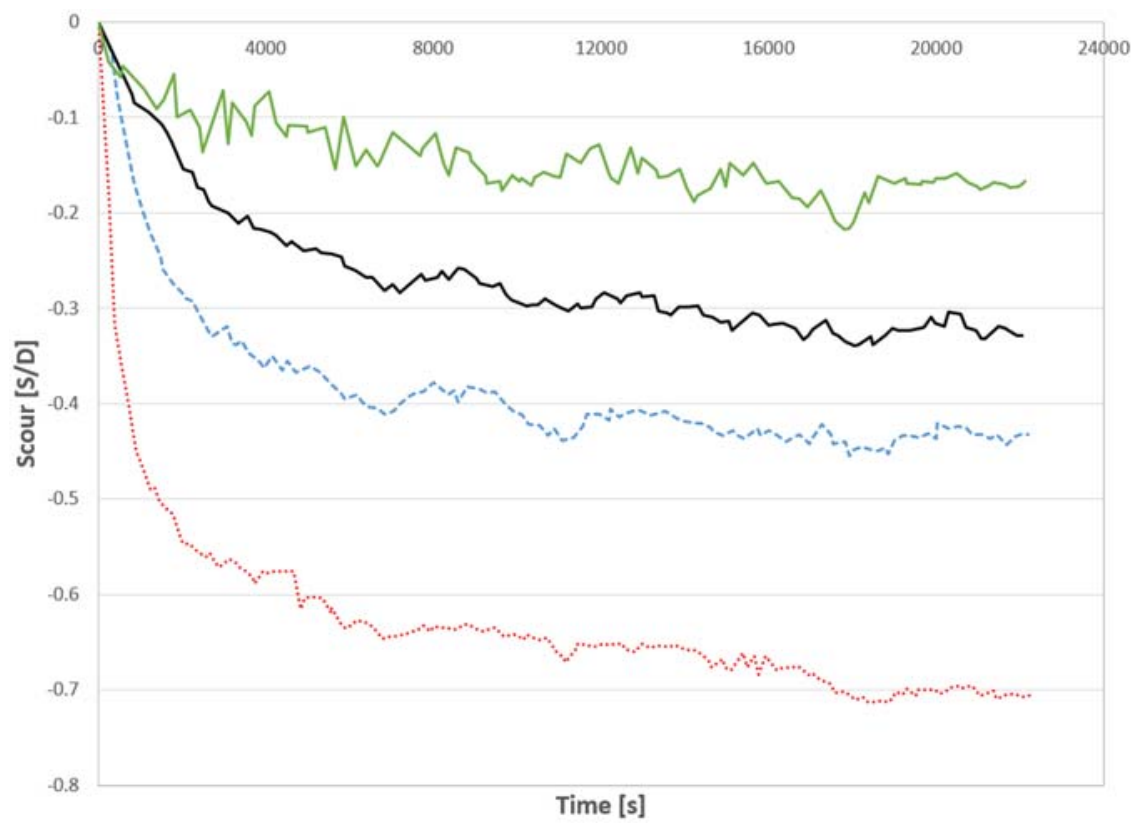

Fig. 19. Lower envelopes for the acoustic sensors for current and $65^{\circ}$ case (round dotted line: Sensor 1, square dotted line: Sensor 2, darker solid line: Sensor 3, top solid line: Sensor 4).

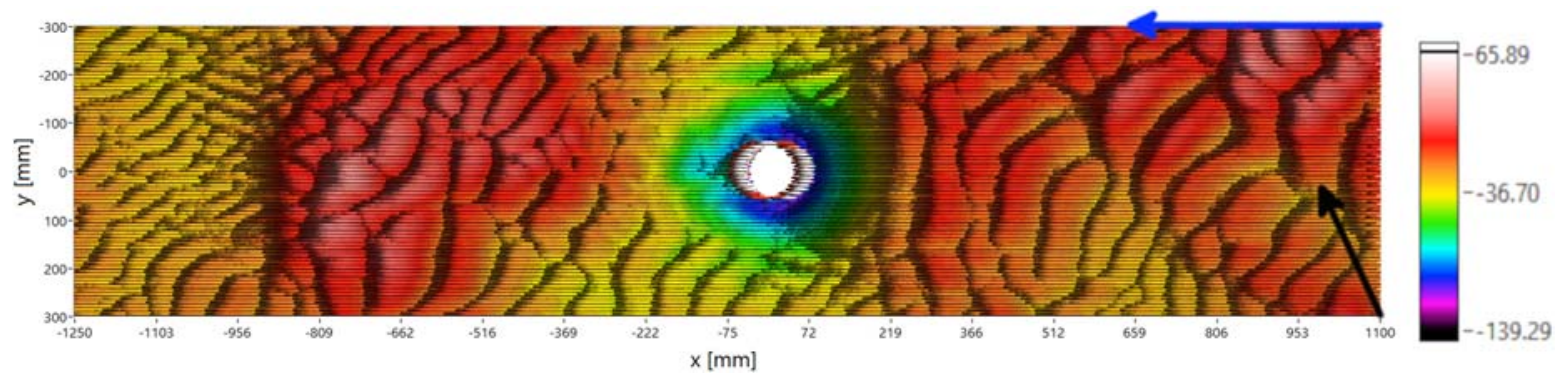

Fig. 20. Level plot showing the final bed morphology for current and $65^{\circ}$ case. The vertical scale units are millimeters. Top right arrow indicates current direction and bottom right arrow indicates the wave propagation direction. 
ripples are present in this case as well. The angle of the ripple crests in the upstream region of the monopile is less regular when compared with the previous case. Close to the monopile the ripples tend to appear almost perpendicular to the flow. In general, the angle appears to be smaller than the previous case, which is consistent with the forcing conditions. In addition, the ripple wavelengths are longer. Downstream of the monopile, a deposition region is again visible. The maximum height of this region is $28 \mathrm{~mm}$ above the starting bed level, which is significantly smaller than the current-only case. The $y=0$ profile is shown in Fig. 21. The scour hole slope in the region $x \in[100,200]$ is $32.4^{\circ}$.

\section{Current and $115^{\circ}$ Waves}

A test was run with currents at $0.27 \mathrm{~m} / \mathrm{s}$ and waves at an angle of $115^{\circ}$ to the currents. Waves were therefore broadly traveling "against" the current, but still at an angle to it. The test was left running for $6 \mathrm{~h}$ when it reached the equilibrium. Fig. 22 shows the lower envelopes of each of the acoustic sensors for this case.

The final sand bed morphology is shown in Fig. 23. The current moves from right to left and the wave front from left to right, bottom to top. The ripples upstream of the monopile form a regular angle with the flow of approximately $132^{\circ}$ with a shorter wavelength

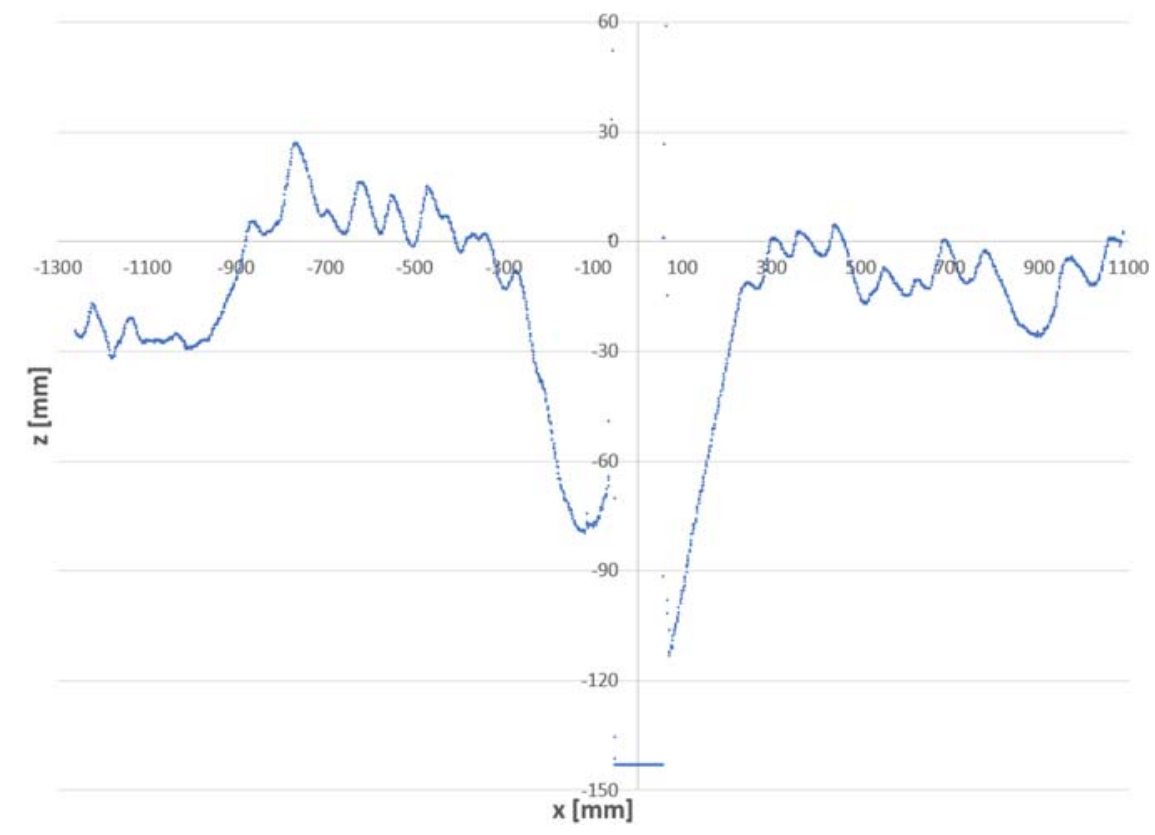

Fig. 21. Profile shape (at $y=0$ ) for current and $65^{\circ}$ waves case at the end of the test, $z=0$ indicates the bed level at the start of the test.

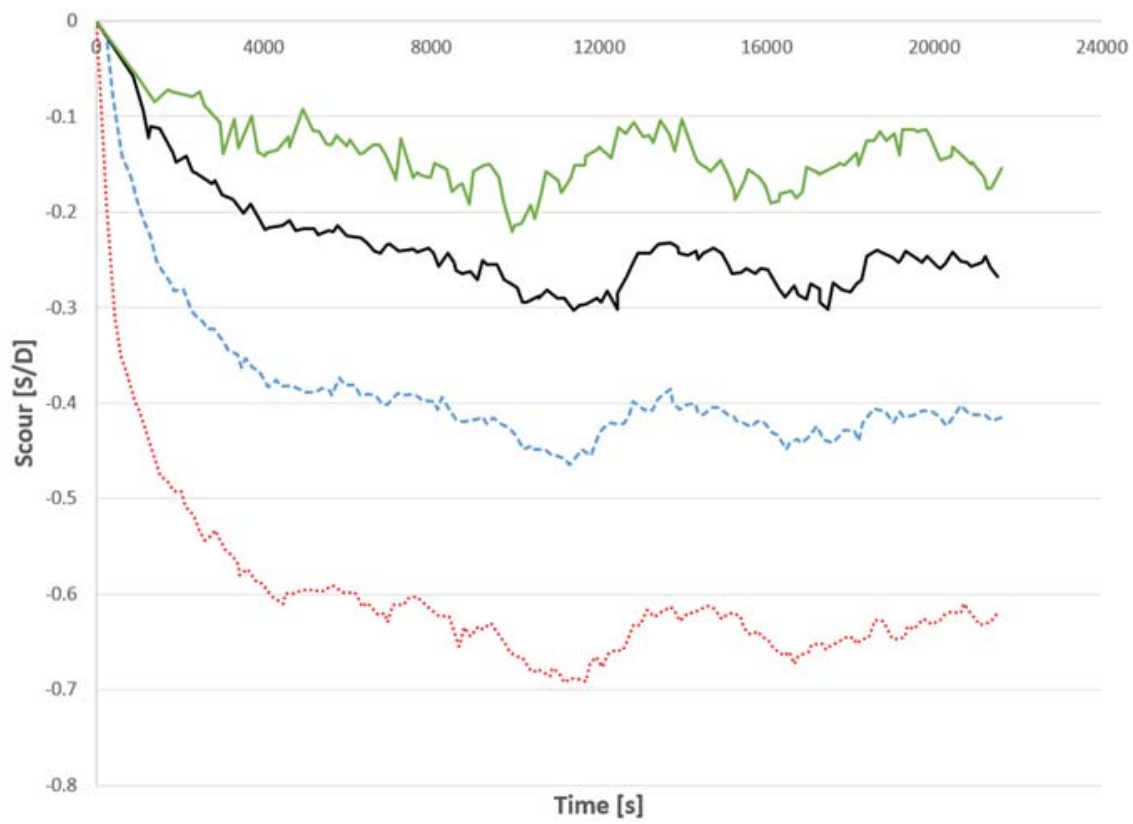

Fig. 22. Lower envelopes for the acoustic sensors for current and $115^{\circ}$ case (round dotted line: Sensor 1, square dotted line: Sensor 2, darker solid line: Sensor 3, top solid line: Sensor 4). 


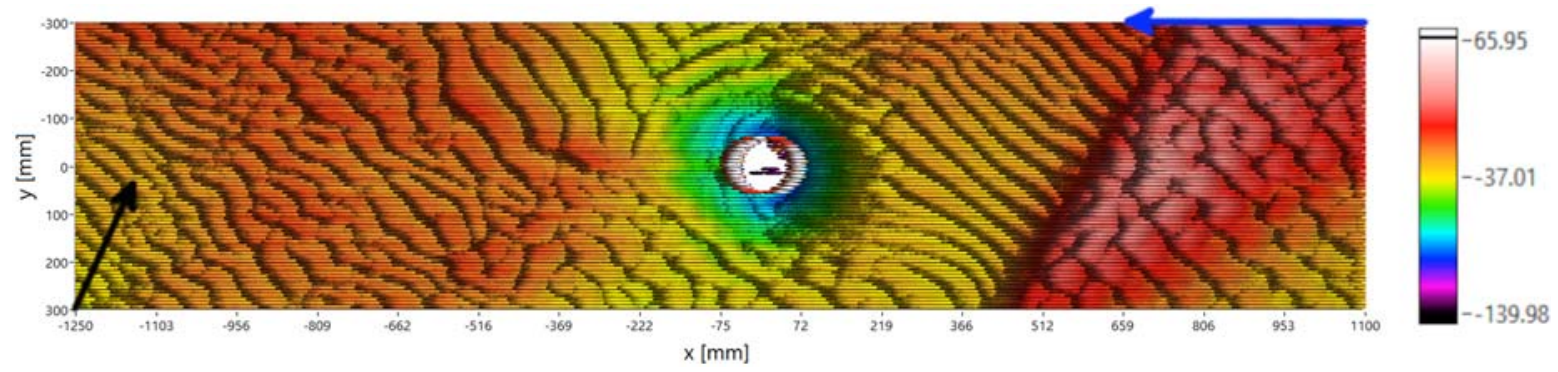

Fig. 23. Level plot showing the final bed morphology for current and $115^{\circ}$ case. The vertical scale units are millimeters. Top right arrow indicates current direction and the bottom left arrow indicates the wave propagation direction.

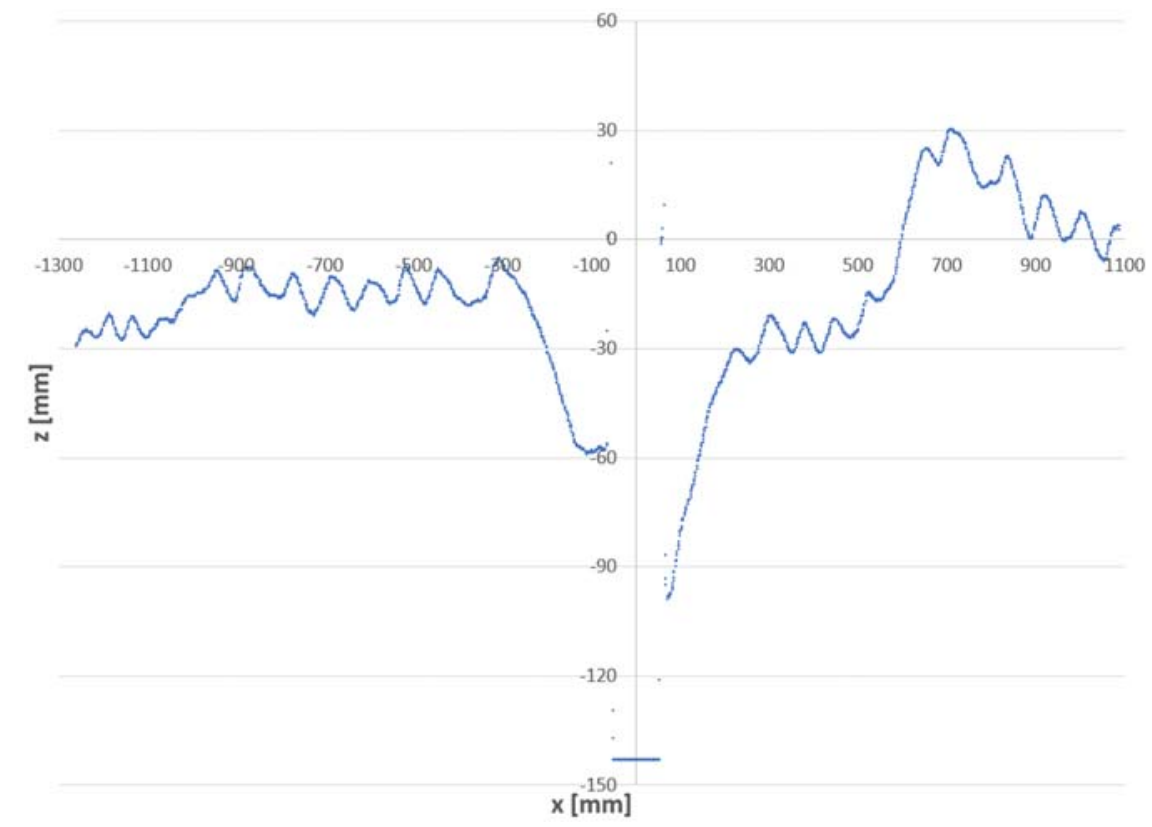

Fig. 24. Profile shape (at $y=0$ ) for current and $115^{\circ}$ waves case at the end of the test, $z=0$ indicates the bed level at the start of the test.

Table 2. Equilibrium scour depths $\left(S_{\mathrm{MAX}}\right)$, scour hole edge slopes, and scour hole areas $\left(A_{s}\right)$ for the different acoustic sensors and tested cases

\begin{tabular}{lcccc}
\hline Case & $S_{\text {MAX }}(S / D)$ & Hole slope $\left(^{\circ}\right)$ & $A_{s}\left(\mathrm{~cm}^{2}\right)$ & $A_{p}(\%)$ \\
\hline Current-only & -0.841 & 32.5 & 2,163 & 76.5 \\
Current and $90^{\circ}$ & -0.669 & 30.9 & $2,278.9$ & 80.6 \\
Current and $65^{\circ}$ & -0.704 & 32.4 & $2,295.9$ & 81.2 \\
Current and $115^{\circ}$ & -0.632 & 23.8 & $2,493.8$ & 88.2 \\
\hline
\end{tabular}

than any of the other tested cases. The $y=0$ profile is shown in Fig. 24. The scour hole slope in the region $x \in[100,200]$ is $23.8^{\circ}$, which is also smaller than the rest of the tested scenarios.

There is a clear line changing the profile of the bed upstream of the monopile from approximately $(x, y)$ : [400, 300] to [660, -100], suggesting an area of accretion in the upstream region of the test area, away from the pile. The source of sand was found some meters upstream where the vertical flow at the outlet of the pumps rolled over to move horizontally within the basin and formed a vortex above the sand. This vortex produced a significant scour hole at the edge of the sand box, and the sand leaving that hole was transported by the forcing conditions. In this case the sand was deposited within the scanned area. This phenomenon also occurred in all the rest of the tested cases (current-only, and current and waves), but the deposition area was also upstream of the scanned area and, hence, not visible in the results. While this is not ideal, the results obtained in the vicinity of the monopile were not affected by this phenomenon.

\section{Discussion}

\section{Scour Depth}

The maximum scour depths found for the different cases are summarized in Table 2. The maximum scour depth is best represented by Sensor 1 due to its relative location above the scour hole, as shown schematically in Fig. 7. Table 2 also gives the hole slope for $x \in[100,200]$. To better visualize the scour hole area, the sand bed level plots (Figs. 10, 17, 20 and 23) were intersected with a $z=-2.99 \mathrm{~cm}$ level, which is the equilibrium scour for Sensor 4 under current-only conditions. Fig. 25 shows all the areas below that threshold for the four cases. To restrict the analysis to the area around the monopile, a $D_{p}=4.8 \cdot D$ circle centered at $(x, y)=0,0$ has been selected. The size of the area has been chosen so that the ratio $D_{p} / D$ falls within typical ranges of scour protection reported in literature for laboratory tests (Petersen et al. 2015; Whitehouse et al. 2006; De Vos et al. 2011) and to cover the whole width of the scanned area. The total area $\left(A_{S}\right)$ and percentage 


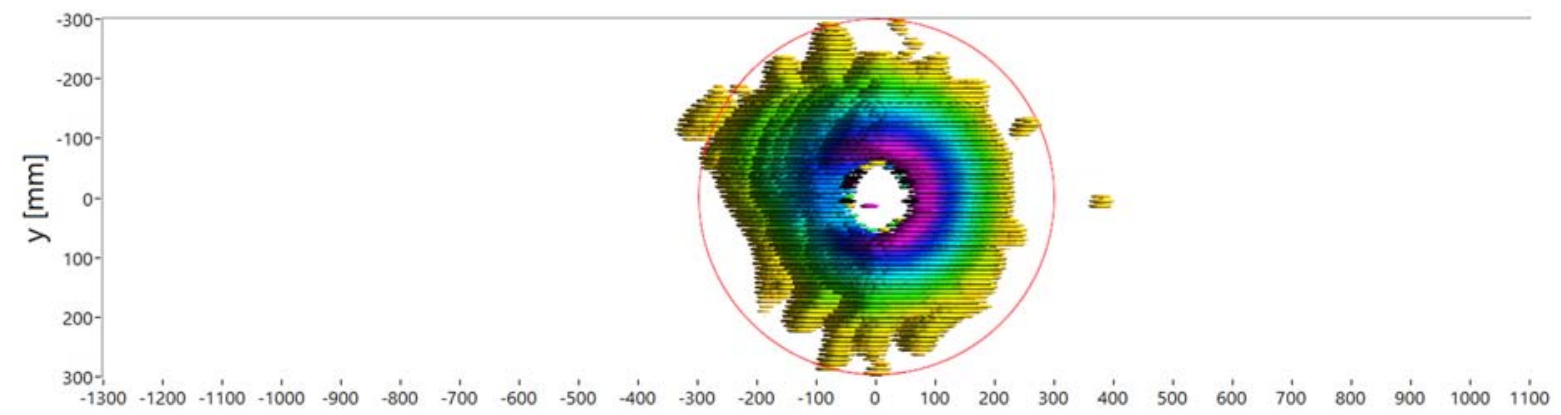

(a)

$\mathrm{x}[\mathrm{mm}]$
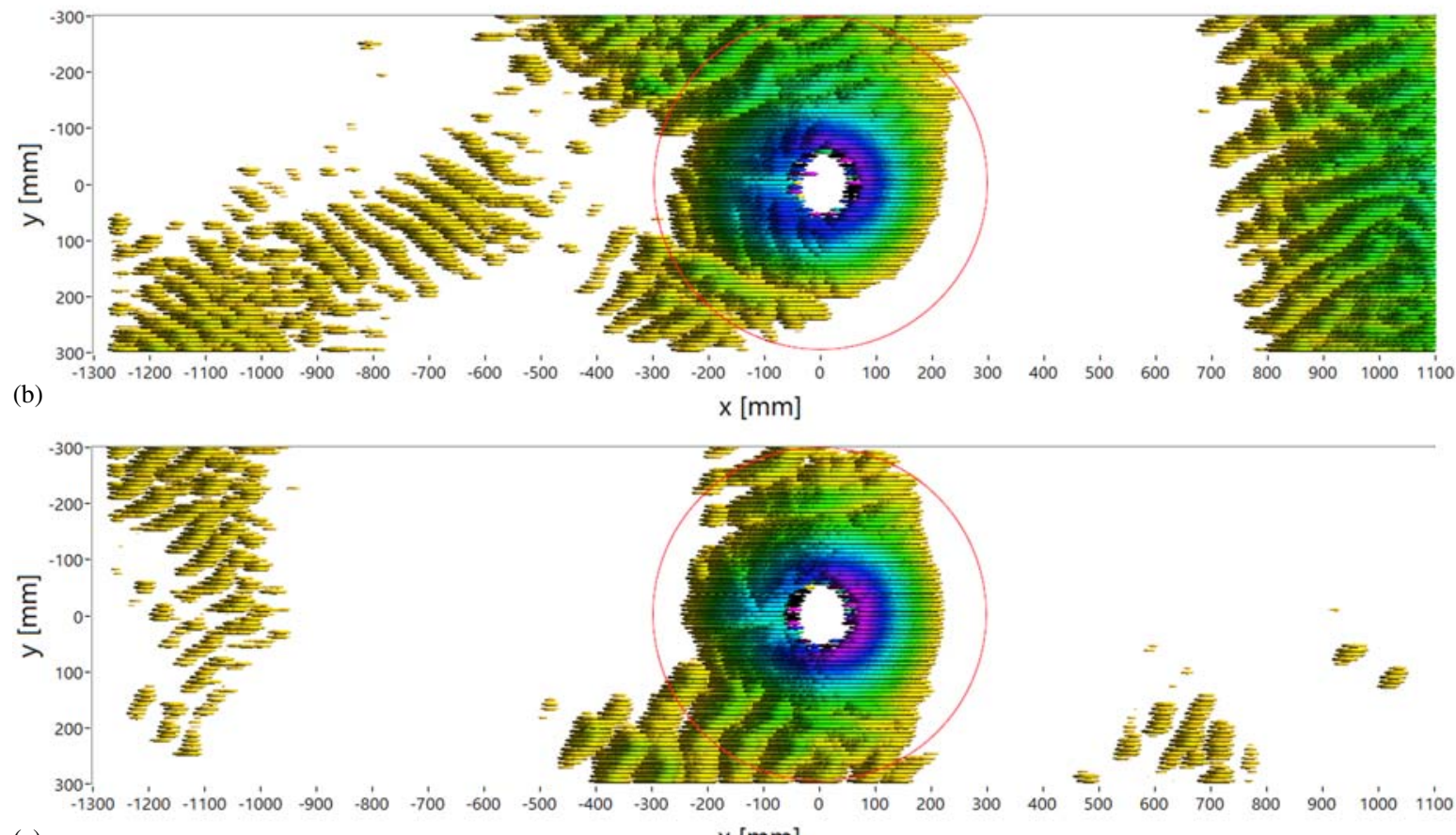

(c)

$\mathrm{x}[\mathrm{mm}]$

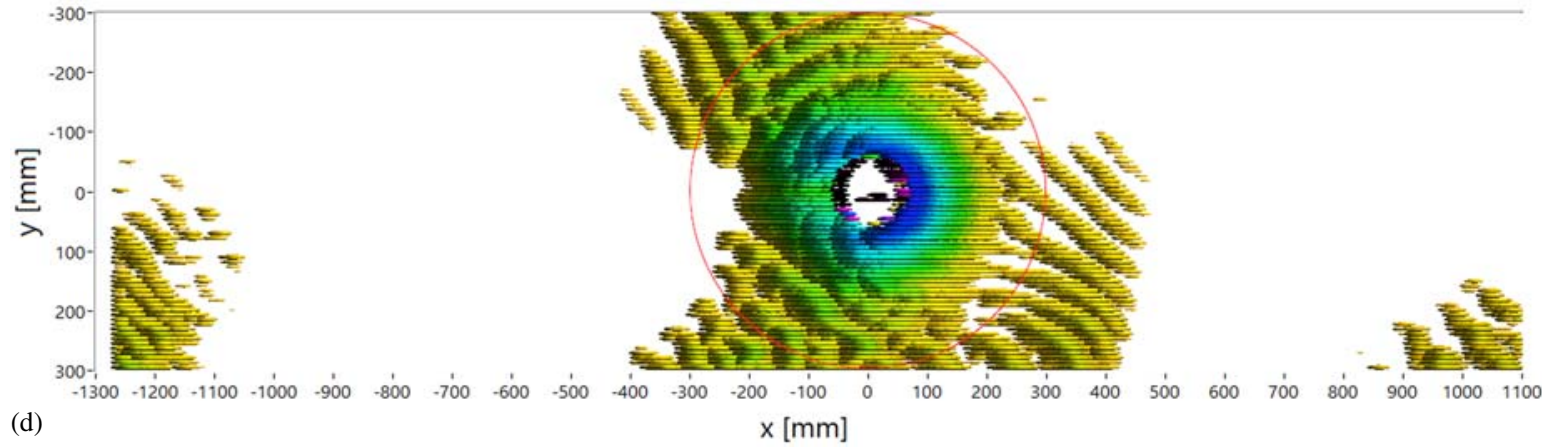

Fig. 25. Areas below an intersection plane $z=-2.99 \mathrm{~cm}$ for (a) current-only case; (b) waves and $90^{\circ}$ case; (c) waves and $65^{\circ}$ case; and (d) waves and $115^{\circ}$ case. A $4.8 \cdot \mathrm{D}$ circle is shown.

of the area $\left(A_{p}\right)$ below the threshold with respect to the area of the circle is summarized in Table 2. The area presented does not include that occupied by the monopile $\left(122.7 \mathrm{~cm}^{2}\right)$.

Results in the literature show different scour responses to waves and currents. De Vos et al. (2012) indicates larger damage to scour protection for waves opposing current. Other authors such as Sumer and Fredsøe (2001) reported very small differences in scour with combined current and opposing or following waves. Soulsby's work indicates that maximum scour happens for waves following the current. These data extend this work to analyzing waves at angles to the current, indicating that oblique waves with the current give slightly more scour than oblique waves against the current.

As observed in the numerical results, the combined action of waves and current seems to reduce the maximum scour depth (for all angles), which is consistent with the existing literature (Sumer and Fredsøe 2002; Rudolph and Bos 2006). According to the results given in Table 2, the wave/current angle seems to have a measurable effect on the maximum scour depth. In fact, among the three cases with a combined action of waves and current, the deepest scour is found for the case when the wave propagation direction was closest to being aligned with the flow $\left(65^{\circ}\right)$ and the 
minimum for the case when the wave propagation direction was closest to being against the flow $\left(115^{\circ}\right)$. Furthermore, if the $90^{\circ}$ waves case is taken as a reference, the scour for the $65^{\circ}$ waves increased by $5.3 \%$ and for the $115^{\circ}$ waves decreased by $5.5 \%$, which is consistent with the change in angle as both cases are symmetric scenarios with respect to the orthogonal case $\left( \pm 25^{\circ}\right.$ respectively). The hole slope is also steeper for current-only conditions but very similar to the case with waves aligned with the flow. Waves against the flow noticeably reduce the hole slope compared with the rest of the cases. When analyzing the scour area, it is evident that for the current-only case the scour is restricted to the area around the monopile. The vortices before and after the pile have a limited area of influence before their energy dissipates. The addition of waves spreads the scour area. The scour area is increased most for waves obliquely against the current, coinciding with a reduced scour depth and a reduced scour hole edge slope. When waves are superimposed, there is some evidence that their stirring force together with the net flux combines to produce scour reaching beyond the circumference. Defining an azimuth angle $\theta$

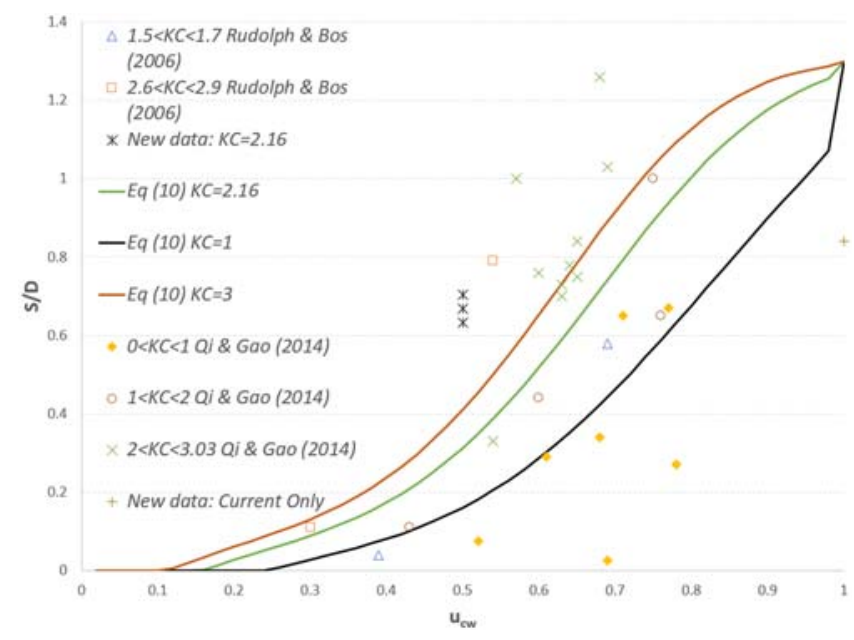

Fig. 26. Scour depth for different $u_{c w}$ values. at $(x, y)=(0,0)$, which is $\theta=0^{\circ}$ for the direction of the incoming flow, these regions can be located for each case. For current and $90^{\circ}$ waves, the regions where the scour goes beyond the circumference are restricted to $\theta \varepsilon\left[50^{\circ}, 156.5^{\circ}\right] \cup\left[204^{\circ}, 232^{\circ}\right]$. For current and $65^{\circ}$ waves, the region is restricted to $\theta \varepsilon\left[203^{\circ}, 296^{\circ}\right]$ and for current and $115^{\circ}$ waves to $\theta \varepsilon\left[80^{\circ}, 160^{\circ}\right] \cup\left[215^{\circ}, 15^{\circ}\right]$. This is interesting because it could help to identify regions prone to suffer edge scour when using scour protection. The current/wave angle seems to have an effect on the locations of these regions. The area upstream of the monopile is mainly free of this phenomenon, indicating that this region is dominated by the flow conditions except when the waves are partially against the current. In general, even though the scour hole is shallower, the area affected by the scour around the monopile is larger with current and waves combined.

The maximum scour depth found in the current-only case is approximately $12.8 \%$ less than the value obtained with Eq. (5) $(S / D=$ 0.841 versus 0.949$)$. The $h / D$ ratio of this test could have a measurable effect on the maximum scour depth according to Ettema (1980). Scour depth increases with flow depth up to a maximum value beyond which there is no influence. In fact, for a $h / D=2.4$, Melville and Sutherland (1988) would expect a 3\% reduction of the maximum scour depth found in deeper flow conditions.

Both sets of Eqs. (6)-(8) and (9)-(11) clearly underpredict the scour depth obtained $[S / D=0.182$ for Eq. (6) and $S / D=0.308$ for Eq. (9)]. Fig. 26 compares the current-only case as well as wave and current at the different angles with data from Rudolph and Bos (2006), Qi and Gao (2014), and the expected scour calculated by Eq. (9) for three different $\mathrm{KC}$ values (1, 2.16, and 3). Very little data have been found for current and waves of low $\mathrm{KC}$ numbers in literature. In the Qi and Gao (2014) experiments, waves are aligned with current (either opposing or following) while in the Rudolph and Bos (2006) experiments, the wave front-current angle is between $60^{\circ}$ and $90^{\circ}$. However, since Rudolph and Bos (2006) agreed with Sumer and Fredsøe (2001) giving little importance to the wave front-current angle, the data are plotted together. As observed, Eq. (9) seems to underpredict the scour even for the Rudolph and Bos (2006) data set in forcing conditions similar to those used in this paper.

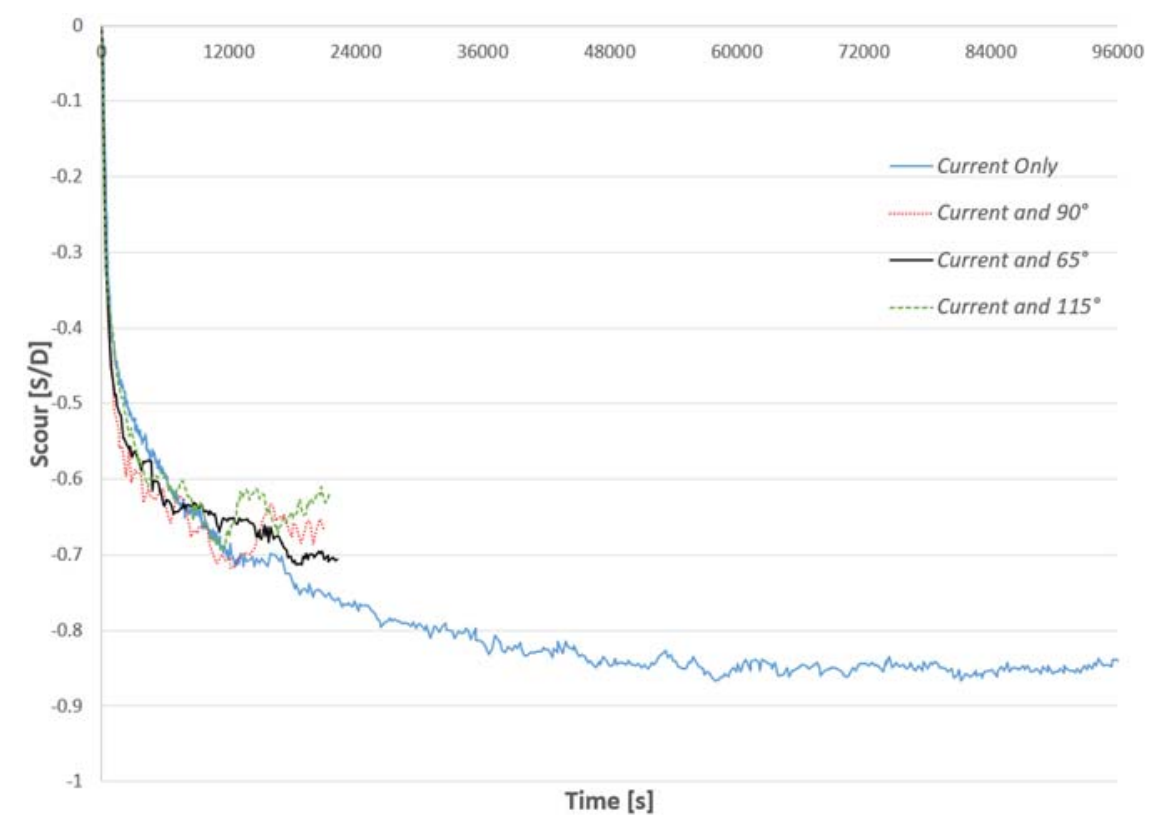

Fig. 27. Time evolution of the maximum scour depth for each tested case. 
The numerical values obtained for the cases of combined action of waves and current seem to point out the measurable effect of the wave/current angle on the scour depth.

\section{Time Evolution}

There was a significant change in the scouring process between the different cases tested, as observed in the time plots (Fig. 27). Current-only scour evolution has a much longer timescale than any combination of waves and current. To analyze the rate of scour evolution, the time required to obtain a $50 \%$ and a $75 \%$ of the maximum scour $\left(S_{\max }\right)$ has been determined for all the cases. The results (Table 3) present the difference between the current-only case and the combination of current and waves. For any of the wave plus

Table 3. Time required to produce a $50 \%$ and $75 \% S_{\max }$ depth hole

\begin{tabular}{lcccrc}
\hline & $S_{\max }$ & $0.5 \cdot S_{\max }$ & $0.75 \cdot S_{\max }$ & & \\
Case & $(S / D)$ & $(S / D)$ & $(S / D)$ & $t_{50 \%}(s)$ & $t_{75 \%}(s)$ \\
\hline Current-only & -0.841 & -0.421 & -0.63 & 1,040 & 7,282 \\
Current and $90^{\circ}$ & -0.669 & -0.335 & -0.502 & 486 & 1,162 \\
Current and $65^{\circ}$ & -0.704 & -0.352 & -0.528 & 531 & 1,882 \\
Current and $115^{\circ}$ & -0.632 & -0.316 & -0.474 & 463 & 1,512 \\
\hline
\end{tabular}

Table 4. Scour rates $(\mathrm{cm} / \mathrm{min})$ of each case for the first half and the third quartile

\begin{tabular}{lcc}
\hline Case & $\begin{array}{c}d z / d t(0 \%-50 \%) \\
(\mathrm{cm} / \mathrm{min})\end{array}$ & $\begin{array}{c}d z / d t(50 \%-75 \%) \\
(\mathrm{cm} / \mathrm{min})\end{array}$ \\
\hline Current & -0.303 & -0.025 \\
Current and $90^{\circ}$ & -0.516 & -0.186 \\
Current and $65^{\circ}$ & -0.497 & -0.098 \\
Current and $115^{\circ}$ & -0.512 & -0.113 \\
\hline
\end{tabular}

Table 5. $A$ and $B$ coefficients and least square difference for Eqs. (14) and (15)

\begin{tabular}{|c|c|c|c|c|c|c|}
\hline \multirow[b]{2}{*}{ Case } & \multicolumn{3}{|c|}{ Eq. (14) } & \multicolumn{3}{|c|}{ Eq. (15) } \\
\hline & $A(S / D)$ & $B(\mathrm{~s})$ & $r$ & $A(S / D)$ & $B\left(\mathrm{~s}^{-1}\right)$ & $r$ \\
\hline Current-only & -0.807 & $3,989.2$ & 0.666 & -0.859 & $4.4 \times 10^{-4}$ & $0.1^{\prime}$ \\
\hline Current and $90^{\circ}$ & -0.662 & 906.2 & 0.157 & -0.697 & $2.04 \times 10^{-3}$ & 0.08 \\
\hline Current and $65^{\circ}$ & -0.659 & $1,060.4$ & 0.214 & -0.701 & $1.57 \times 10^{-3}$ & 0.054 \\
\hline Current and $115^{\circ}$ & -0.634 & $1,121.8$ & 0.129 & -0.670 & $1.66 \times 10^{-3}$ & 0.071 \\
\hline
\end{tabular}

current cases, the time required to produce a $50 \% S_{\max }$ depth hole is approximately half the time required by the current-only case. The next quartile shows even larger differences as confirmed by the different slopes in the time evolution plot. A total of $75 \%$ of the maximum scour depth for waves and currents was achieved in approximately $25 \%$ of the time for current-only. The wave/current angle seems to have an effect in the time evolution as well. Waves generally with currents $\left(65^{\circ}\right.$ here) appear to give slightly slower scour development than the other cases that have waves.

Table 4 presents the different scour rates for the first half of the process $\left(t_{0 \%}-t_{50 \%}\right)$ and the third quartile $\left(t_{75 \%}-t_{50 \%}\right)$. All waves plus current cases are significantly faster than current-only. The third quartile's rate becomes significantly slower than the first half for all the cases.

Sheppard et al. (2004) compared the following equations for their large-scale experiment to describe the scour evolution:

$$
\begin{gathered}
S(t)=A \cdot\left(1-e^{-(t / B)}\right) \\
S(t)=A \cdot\left(1-\frac{1}{1+B t}\right)
\end{gathered}
$$

The performance of these equations was tested for current speeds of $0.27 \mathrm{~m} / \mathrm{s}$ and waves from 90,65 , and 115 degrees. The scour depth next to the sensor (Sensor 1) was plotted as a function of time and used to identify both Parameters A and B in Eqs. (14) and (15) (Fig. 28). In calculating the predicted scour depths, a value of $A=S_{\max }$ is taken as a first guess to start the iterative process. A and B were found by best fitting using a least squares approach for each of the tested cases. Table 5 gives the coefficients found and the obtained $r=(1 / n) \sum\left(y_{t_{i}}-S\left(t_{i}\right)\right)^{2}$ for Eqs. (14) and (15). The lower value of B for currents plus waves in Eq. (14) [and the larger value of B in Eq. (15)] reflects the fact that the scour develops more quickly in the current plus wave cases.

In general, Eq. (15) seems to minimize the error more than Eq. (14) and hence more accurately predict the scour evolution in time. The predicted maximum scour for both equations shows good agreement with the experimental results with a maximum error between predicted and measured bed elevation of $6.4 \%$ for Eq. (14) and of $6.1 \%$ for Eq. (15). Fig. 28 shows the modeled and measured time series of scour obtained with the acoustic Sensor 1 for current-only as well as current and $115^{\circ}$ and Eqs. (14) and (15) superimposed.
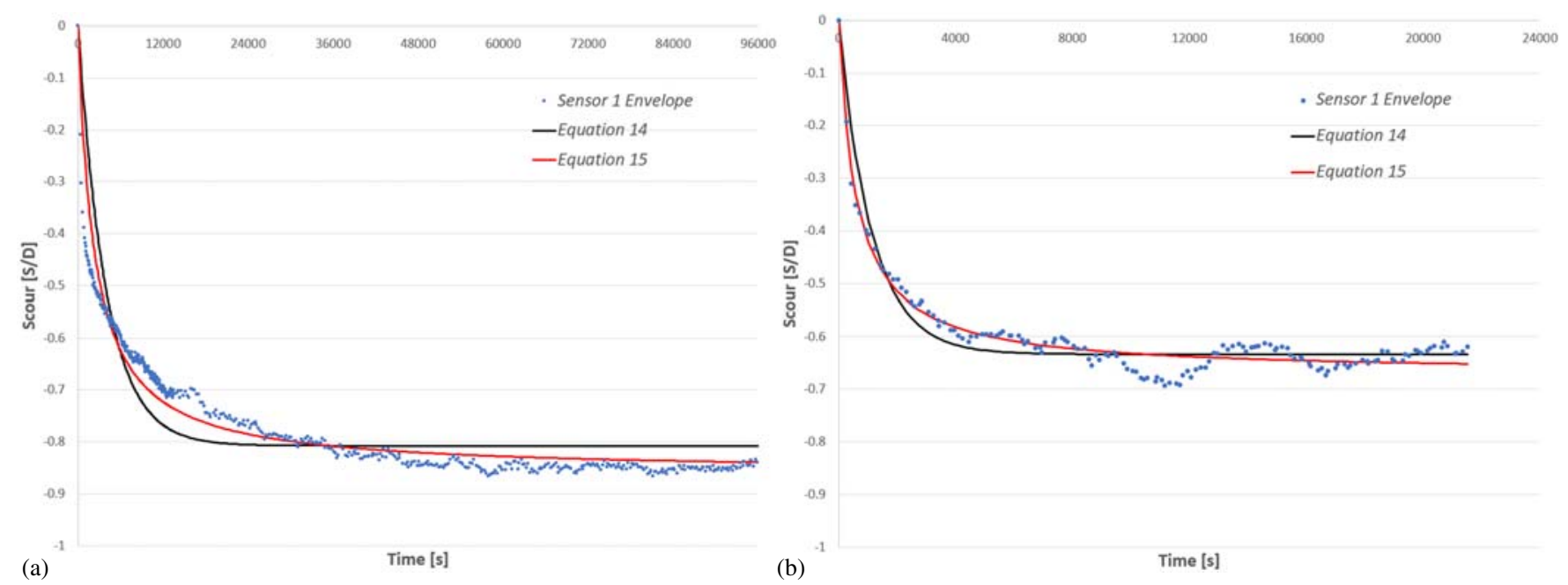

Fig. 28. Time evolution for (a) current-only; and (b) current and $115^{\circ}$, with Eq. (14) (darker solid line) and Eq. (15) (clearer solid line) regressions superimposed. 
The superimposition of waves and current seems to add a periodic oscillation to the time evolution, similar to what is expected in live-bed scour conditions according to Chabert and Engeldinger (1956). This is probably due to wave ripples near the scour hole edge collapsing into the monitored area.

The work presented in this paper it is of particular interest to those involved in offshore engineering looking to place monopile foundations in regions of mobile sediments. For offshore windfarm monopile applications in particular, understanding the scour response to both waves and currents is important both for monopile stability and for export cable design and protection.

\section{Conclusions}

An experimental study of the influence of the wave/flow angle on the scour generated around a monopile has been carried out.

The scour found under current-only conditions is $12.8 \%$ less than what Zanke (1982) equation predicts. On the other hand, scour under both waves and current is significantly higher than what Sumer and Fredsøe (2001) and Rudolph and Bos (2006) predicted with their respective equations. Compared with other experimental results found in literature for similar $\mathrm{KC}$ numbers, they show similar deviation from these equations.

The results show that there is a measurable effect both on the maximum scour depth generated and in the time evolution of the process. Waves with propagation directions aligned at an angle to the flow, but generally with the flow direction, produce deeper scour holes than an orthogonal wave-current combination. Waves propagating generally against the flow produce a less deep scour hole. Any combination of waves superimposed on the current reduces the scour generated when compared with current-only conditions.

The rate of scour development is enhanced when waves are added to the current case. A total of $50 \%$ of the maximum scour depth is achieved in approximately half the time, while $75 \%$ of the maximum scour depth is achieved in $25 \%$ of the time.

The results indicate that wave direction relative to the current is an important parameter in controlling both the scour development and the maximum scour near a circular monopile.

\section{Data Availability Statement}

All data, models, or codes that support the findings of this paper are available from the corresponding author upon reasonable request.

\section{Acknowledgments}

The authors would like to thank the contribution of Dr. Kieran Monk, Mr. Gregory Nash, Mr. Peter Arber, Mr. Alastair Reynolds, and Mr. Andrew Oxenham during the test setup and the whole experimental campaign. The research was supported by Intelligent Community Energy (ICE) project, INTERREG V FCE, European Commission (Contract No. 5025).

\section{References}

Arneson, L. A., L. W. Zevenbergen, P. F. Lagasse, and P. E. Clopper. 2012. Evaluating scour at bridges. FHWA-HIF-12-003 HEC-18. Washington, DC: FHWA.
Breusers, H. N. C., G. Nicollet, and H. W. Shen. 1977. "Local scour around cylindrical piers." J. Hydraul. Res. 15 (3): 211-252. https://doi.org/10 .1080/00221687709499645.

Chabert, J., and P. Engeldinger. 1956. Etude des affouillements autour des piles de ponts. Chatou, France: Lab. Nat. d'Hydr.

Dean, R., and R. Dalrymple. 1991. Vol. 2 of Water wave mechanics for engineers and scientists. Advanced Series on Ocean Engineering. Singapore World Scientific Publishing.

De Vos, L., J. De Rouck, P. Troch, and P. Frigaard. 2011. "Empirical design for scour protections around monopile foundations Part 1: Static approach." Coastal Eng. J. 58 (6): 540-553. https://doi.org/10.1016/j .coastaleng.2011.02.001.

De Vos, L., J. De Rouck, P. Troch, and P. Frigaard. 2012. "Empirical design for scour protections around monopile foundations Part 2: Dynamic approach." Coastal Eng. J. 60: 286-298. https://doi.org/10 .1016/j.coastaleng.2011.11.001.

Dey, S. 1999. "Time-variation of scour in the vicinity of circular piers." Water, Maritime and Energy, 67-75. London: Institution of Civil Engineers (ICE).

Ettema, R. 1980. "Scour at bridge piers." Ph.D. thesis, School of Engineering, Univ. of Auckland.

Fazeres-Ferradosa, T., J. Chambel, F. Taveira-Pinto, P. Rosa-Santos, F. V. C. Taveira-Pinto, G. Giannini, and P. Haerens. 2021. "Scour protections for offshore foundations of marine energy harvesting technologies: A review." J. Mar. Sci. Eng. 9: 297. https://doi.org/10.3390 /jmse9030297.

Fenton, J. D. 1985. "A fifth-order stokes theory for steady waves." J. Waterway, Port, Coastal, Ocean Eng. 111: 216-234. https://doi.org /10.1061/(ASCE)0733-950X(1985)111:2(216).

Harris, J. M., R. J. S. Whitehouse, and T. Benson. 2010. "The time evolution of scour around offshore structures." Proc. Inst. Civ. Eng. Marit. Eng. 163 (1): 3-17. https://doi.org/10.1680/maen.2010.163.1.3.

Hartvig, P. A., J. M. Thomsen, P. Frigaard, and T. L. Andersen. 2010. "Experimental study of the development of scour and backfilling." Coastal Eng. J. 52 (2): 157-194. https://doi.org/10.1142/S0578563410002154.

Hoffmans, G. J. C. M., and H. J. Verheij. 1997. Scour manual. Rotterdam, Netherlands: Balkema.

Jain, S. C., and E. E. Fischer. 1979. Scour around circular bridge piers at high Froude Numbers. FHWA-RD-79-104. Washington, DC: FHWA.

Melville, B. W., and A. Sutherland. 1988. "Design method for local scour at bridge piers." J. Hydraul. Eng. 114 (10): 1210-1226. https://doi.org /10.1061/(ASCE)0733-9429(1988)114:10(1210).

Petersen, T. U., M. Sumer, J. Fredsoe, T. Raaijmakers, and J.-J. Schouten. 2015. "Edge scour at scour protections around piles in the marine environment - Laboratory and field investigation." Coastal Eng. 106: 4272. https://doi.org/10.1016/j.coastaleng.2015.08.007.

Pizarro, A., S. Manfreda, and E. Tubaldi. 2020. "The science behind scour at bridge foundations: A reivew." Water 12 (2): 374. https://doi.org/10 $.3390 / w 12020374$.

Qi, W.-G., and F.-P. Gao. 2014. "Physical modeling of local scour development around a large-diameter monopile in combined waves and current." Coastal Eng. 83: 72-81. https://doi.org/10.1016/j.coastaleng 2013.10.007.

Raudkivi, A. J., and R. Ettema. 1983. "Clear-water scour at cylindrical piers." J. Hydraul. Eng. 109 (3): 338-350. https://doi.org/10.1061 /(ASCE)0733-9429(1983)109:3(338).

Rudolph, D., and K. Bos. 2006. "Scour around a monopile under a combined wave-current conditions and low KC-numbers." In Proc., 6th Int. Conf. on Scour and Erosion, 582-588. Amsterdam, The Netherlands: CURNET.

Schendel, A., A. Hildebrandt, and T. Schlurmann. 2018. "Experimental study on scour around a pile in multidirectional (spreading) random waves." In Proc., 9th Int. Conf. on Scour and Erosion, edited by Keh-Chia. London: Taylor \& Francis.

Schendel, A., M. Welzel, T. Schlurmann, and T.-W. Hsu. 2020. "Scour around a monopile induced by directionally spread irregular waves in combination with oblique currents." Coastal Eng. 161: 103751. https://doi.org/10.1016/j.coastaleng.2020.103751.

Shen, H. W., V. R. Schneider, and S. S. Karaki. 1966. Mechanics of local scour. Fort Collins, CO: Colorado State Univ. 
Sheppard, D. M., M. Odeh, and T. Glasser. 2004. "Large scale clear-water local pier scour experiments." J. Hydraul. Eng. 130 (10): 957-963. https://doi.org/10.1061/(ASCE)0733-9429(2004)130:10(957).

Sumer, M., and J. Fredsøe. 2001. "Scour around pile in combined waves and current." J. Hydraul. Eng. 127 (5): 403-411. https://doi.org/10 .1061/(ASCE)0733-9429(2001)127:5(403).

Sumer, M., and J. Fredsøe. 2002. "The mechanics of scour in the marine environment." Adv. Ser. Ocean Eng. 17: 552. https://doi.org/10.1142/4942.

Sumer, M., J. Fredsøe, and N. Christiansen. 1992. "Scour around vertical pile in waves." J. Waterway, Port, Coastal, Ocean Eng. 118 (1): 15-31. https://oi.org/10.1061/(ASCE)0733-950X(1992)118:1(15).

Sumer, M., T. Petersen, L. Locatelli, J. Fredsoe, R. Musumeci, and E. Foti. 2013. "Backfilling of a scour hole around a pile in waves and current." J. Waterway, Port, Coastal, Ocean Eng. 139 (1): 9-23. https://doi.org /10.1061/(ASCE)WW.1943-5460.0000161.
Welzel, M., A. Schendel, A. Hildebrandt, and T. Schlurmann. 2019. "Scour development around a jacket structure in combined waves and current conditions compared to monopile foundations." Coastal Eng. 152: 103515. https://doi.org/10.1016/j.coastaleng.2019.103515.

Whitehouse, R. J. S., J. Sutherland, and D. O'Brien. 2006. "Seabed scour assessment for offshore windfarm." In Proc., 3rd Int. Conf. on Scour and Erosion, 698-707. Amsterdam, The Netherlands: CURNET.

Zanke, U. 1978. Coherence between current and sediment transport. Part I calculation of sediment transport-general case-. Hannover: Mitt. Des Franzius-Instituts der Univ., Heft 47.

Zanke, U. 1982. Grundlagen der Sedimentbewegung. Berlin: Springer.

Zanke, U., T.-W. Hsu, A. Roland, O. Link, and R. Diab. 2011. "Equilibrium scour depths around piles in noncohesive sediments under currents and waves." Coastal Eng. 58 (10): 986-991. https:// doi.org/10.1016/j.coastaleng.2011.05.011. 